\title{
Numerical Analysis of Concrete Gravity Dam Seepage Characteristics Evolution considering the Calcium Leaching Effect
}

\author{
Kailai Zhang $\mathbb{D},{ }^{1}$ Liqun Xu $\mathbb{D},{ }^{1}$ Liting Qiu $\mathbb{D},{ }^{2}$ Jiacheng Tan $\mathbb{D},{ }^{1}$ Chao Yang $\mathbb{D},{ }^{1}$ \\ and Kai Zhang $\mathbb{1}^{3}$ \\ ${ }^{1}$ College of Water Conservancy and Hydropower Engineering, Hohai University, Nan Jing, Jiangsu 210098, China \\ ${ }^{2}$ Nanjing Hydraulic Research Institute, Nanjing, Jiangsu 210098, China \\ ${ }^{3}$ Shanghai Investigation, Design and Research Institute Co., Ltd., Shanghai, China
}

Correspondence should be addressed to Liqun Xu; xlq@hhu.edu.cn

Received 13 December 2019; Revised 15 July 2021; Accepted 26 October 2021; Published 19 November 2021

Academic Editor: José Aguiar

Copyright ( 2021 Kailai Zhang et al. This is an open access article distributed under the Creative Commons Attribution License, which permits unrestricted use, distribution, and reproduction in any medium, provided the original work is properly cited.

During the long-term service life of hydraulic structures, the calcium compounds in cement-based materials decompose in the aqueous environment, leading to the continuous change of seepage characteristics. To study the influence of calcium leaching on the concrete dam seepage characteristics, we proposed a new mathematic model of the cement-based material calcium leaching model under advection-diffusion-driven leaching. A solid-liquid nonequilibrium model is adopted to model the decomposition of calcium hydroxide $(\mathrm{CH})$ and calcium silicate hydrate gel (C-S-H). To calculate the porosity more accurately, the proposed model takes the effect of different calcium compound decomposition on the porosity increase in consideration, respectively. Shimantan dam is selected for the three-dimensional (3D) calcium leaching analyses. The 3D finite element model of this dam is analyzed using COMSOL Multiphysics software that is based on the finite element method. Based on the proposed model, seepage characteristics evolutions of the Shimantan dam are studied. Good agreement between the numerical results and the monitored data indicates the accuracy of this simulation. The result shows that after 100 a leaching duration, the uplift pressure increases by $40.8 \%$, and the leakage quantities of the dam body and foundation increase by 48 and 17 times. The rise of uplift pressure and leakage changes caused by curtain deterioration are the main influences of calcium leaching on the dam seepage. The parameter sensitivity results show that it is necessary to reduce $\mathrm{CH}$ content in cement-based materials to obtain better calcium leaching durability. This model and simulation results can guide the operation of concrete dams under advection-diffusion-driven leaching.

\section{Introduction}

Roller-compacted concrete gravity dams have been widely built worldwide due to their shorter construction duration, lower cost, and convenience. Seepage is one of the critical problems in dam operation. Seepage characteristics are closely related to concrete gravity dam safety. Uplift pressure and exit gradient values are the leading causes of different dam failures [1]. Accurate seepage analysis of hydraulic structures is a challenging task [2]. Over their long terms of service, the decomposition of calcium compounds such as that in the form of calcium hydroxide $(\mathrm{CH})$ and calcium silicate hydrate gel (C-S-H) is evitable since the $\mathrm{pH}$ of the aqueous environment $(\mathrm{pH}=7)$ is much lower than that of the concrete pore solution $(\mathrm{pH}=12.5-13[3,4])$. Under the effect of the concentration gradient, calcium ions leach into the aqueous environment, causing increasing porosity and permeability and degrade material nature. As a result, the seepage characteristic of concrete dams will constantly change in the leaching process.

For example, Fengman concrete gravity dam was built in the year 1937. The impoundment started in the year 1942. After nearly 80 years of operation, Fengman concrete gravity was demolished and rebuilt due to severe leakage and concrete deterioration problems. The aggregate and mortar in the dam concrete are separated, and binding contents almost leached out. Honeycombs and cavities are common in all dam sections. Calcium leaching is the foremost cause of leakage and concrete deterioration of Fengman dam [5]. Gutianxi flat slab buttress dam started to impound in the 
year 1961. In 1990, there were four dam sections with serious leakage and seven dam sections with calcium leaching. In 2000, there were eight dam sections with serious leakage, twenty dam sections with calcium leaching. The overall strength of concrete slabs is decreased from $49.6 \mathrm{MPa}$ to $37.9 \mathrm{MPa}$ by $23.6 \%$ [6].

Calcium leaching has an obvious effect on the diffusivity $[7,8]$, permeability $[3,4]$, and strength $[9-14]$ evolution of cement-based materials. The development of the calcium leaching model could guide the operation of hydraulic structures. For modelling research of the calcium leaching process, solid-liquid equilibrium equation has been widely used [15-19]. This equation is a phenomenological chemical equilibrium model relating the calcium concentration of the skeleton and the pore solution on the concept of isotropic damage mechanics [20]. Kamali et al. [21, 22] proposed a simplified model to predict the leaching depth considering the initial porosity, water-cement ratio, temperature, and solution composition. For leached sample mechanical properties, Kuhl [20,23] proposed the changing mechanical and transport properties are related to the total porosity and calculated $e$ porosity with average molar volume. Since then, scholars have proposed series of chemomechanical models considering damage mechanics behaviour [24-29], the multiscale effect $[17,30,31]$, creep, and damage behaviour [32]. These models assume a local thermodynamic equilibrium between calcium compounds in the solid skeleton and calcium ions in the pore solution. The leaching process is driven by diffusion. We can calculate the calcium compound decomposition rate with the solid-liquid equilibrium curve. For advection-diffusion-driven leaching, the thermodynamic equilibrium state is broken. Therefore, we should not calculate the leaching rate from the solid-liquid curve. Ulm [33] proposed a relation describing the calcium compounds decomposition rate for advection-diffusion-driven leaching in cement-based materials based on chemoporoplasticity theory. When there is a sudden change in capillary $\mathrm{Ca}^{2+}$ concentration, the decomposition rate is dependent on the actual "distance" from the equilibrium curve [34]. Gawin [34-36] adopted Ulm's rate equation and proposed a hydrochemomechanical model of cementitious materials exposed to contact with deionized water. In the calculation of porosity, Gawin adopted Kuhl's calculation method [20]. The porosity in the leaching process is a function of the average molar volume of different calcium compounds and the total calcium content.

In the existing calcium leaching simulation, the key parameters such as diffusivity and permeability are functions of porosity. However, the porosity is generally calculated with average molar volume and ignored the effect of different calcium compounds decomposition on the porosity evolution. Decomposition of $\mathrm{CH}$ generates capillary pores, while the decomposition of $\mathrm{C}-\mathrm{S}-\mathrm{H}$ generates gel pores and capillary pores. Therefore, to model the leaching process more accurately, especially in the advection-diffusion-driven leaching, we should consider the effect of different calcium compounds decomposition.

The long-term service performance of dams has always been one of the most important research fields in hydraulic engineering [37]. The main focuses of these studies are the evolution of dam deformation and stress. However, as a water storage structure, the long-term seepage characteristic evolution of dams under the effect of calcium leaching has not been investigated in the literature. Seepage characteristics are closely related to dam safety. The evolutions of dam seepage characteristics under the effect of advection-diffusion-driven leaching are closely associated with long-term service safety and benefits and need further exploration.

The objective of this study is to investigate the concrete dam seepage evolution in the leaching process. In the existing advection-diffusion-driven leaching simulation, the porosity is generally calculated with average molar volume and ignored the effect of different calcium compounds decomposition on the porosity evolution. To improve the simulation accuracy, we proposed a new mathematic model of hydrochemo behaviour of cement-based materials. The decomposition of $\mathrm{CH}$ and $\mathrm{C}-\mathrm{S}-\mathrm{H}$ are considered, respectively. Kozeny-Carman (KC) relation is adopted to model the permeability coefficient evolution. Shimantan dam is selected for the three-dimensional (3D) calcium leaching analyses. The 3D finite element model of this dam is modelled using COMSOL Multiphysics software. Based on the proposed model, seepage characteristics evolutions of Shimantan dam are obtained. The accuracy of this simulation is verified by the water head and leakage monitoring data. The influences of initial $\mathrm{CH}$ content and hydraulic conductivity are also discussed. The proposed numerical model can be used to analyze the antiseepage ability deterioration of grout curtains, concrete face slabs, and core walls under the effect of advection-diffusion-driven leaching. These simulation results will guide the dam safety monitoring and evaluation.

The article is organized as follows. First, the basic theory of the model is presented. Then, a numerical example is solved to validate the proposed model. Next, the seepage characteristic evolution of Shimantan concrete gravity dam is analyzed with the presented model. Behind, the influences of $\mathrm{CH}$ content and hydraulic conductivity are discussed. Finally, the conclusions are presented.

\section{Materials and Methods}

The nature of the calcium leaching process of cement-based materials in hydraulic engineering is calcium compounds decomposition in low $\mathrm{pH}$ solutions and then precipitation into the surrounding environment under the concentration gradient and hydraulic gradient. The main chemical reactions equations are given in the following equation [20]:

$$
\begin{aligned}
\mathrm{Ca}(\mathrm{OH})_{2} & \rightleftharpoons \mathrm{Ca}^{2+}+2 \mathrm{OH}^{-} \\
n \mathrm{CaO} \times \mathrm{SiO}_{2} \times n \mathrm{H}_{2} \mathrm{O} & \rightleftharpoons n \mathrm{Ca}^{2+}+\mathrm{H}_{3} \mathrm{SiO}_{4}^{-}+[2 n-1] \mathrm{H}_{2} \mathrm{O}
\end{aligned}
$$

The pore solution of cement-based materials is assumed to be in thermodynamic equilibrium with the calcium compound in the solid skeleton. When the calcium ion concentration of pore solution decreased below $22 \mathrm{~mol} / \mathrm{m}^{3}$, $\mathrm{CH}$ starts to decompose. After the complete decomposition 
of $\mathrm{CH}$ and the calcium ion concentration decreased to $18 \mathrm{~mol} / \mathrm{m}^{3}$, C-S-H starts to decay.

There are two modes of calcium ion transport in hydraulic structures: advection and diffusion. Advection is the convection of calcium ions in the pore solution that flows through porous media. The driven force of advection is the hydraulic gradient. Diffusion is the movement of calcium ions in the pore solution from high ion concentration to low ion concentration. The driven force of diffusion is the concentration gradient.

From the concept of thermodynamic, there are two states between calcium ions in the pore solution and calcium compounds in the solid skeleton: equilibrium state and nonequilibrium state. In the equilibrium state, the decrease in calcium ion concentration induces a thermodynamic imbalance, which drives the decalcification of the solid skeleton until thermodynamic equilibrium is reached [33]. In other words, the values of calcium content in the skeleton are determined by calcium ions concentration in the pore solutions. The driven force of calcium leaching in the equilibrium state is diffusion. In the nonequilibrium state, the decalcification of the solid skeleton will not lead to equilibrium. There is no relation between calcium ion concentration and calcium content in the solid skeleton. The driven force of calcium leaching in the nonequilibrium state is advection.

Figure 1 shows the general sketch of the physical model for calcium leaching in concrete dams. The calcium ion concentration in the water environment is much lower than in the pore solution. Under the concentration gradient and hydraulic gradient effect, the calcium ion, which comes from $\mathrm{CH}$ and C-S-H decomposition, participates into the surrounding water environment. As a result, the porosity and transport properties of dam materials increase. The dam seepage characteristics constantly change in the process of calcium leaching.

Figure 2 shows the calcium leaching phenomenon in corridors of the Shimantan concrete gravity dam overflow sections after 14 years of operation. As we can see from the pictures, the white leached matter cascades down, covering almost the whole inner surface of the corridors. The white leached matter is calcium carbonate, which comes from the carbonization of leached $\mathrm{CH}$.

Figure 3 shows all the phenomena of the calcium leaching process under equilibrium (Figure 3(a)) and nonequilibrium (Figure 3(b)) conditions. Equation (1) shows the decomposition reaction equations of $\mathrm{CH}$ and $\mathrm{C}-\mathrm{S}-\mathrm{H}$. In diffusiondriven leaching, the calcium ion concentration in the pore solution is decreasing gradually. When the calcium concentration of the pore solution falls below a critical level, $\mathrm{Ca}(\mathrm{OH})_{2}$ crystals start to decompose. After all the $\mathrm{CH}$ leaches out, C-S-H begins to deteriorate $[38,39]$. While in advectiondiffusion-driven leaching, calcium ion concentration is lower than the critical concentration of $\mathrm{CH}$ and C-S-H. Therefore, $\mathrm{CH}$ and C-S-H decompose simultaneously. According to the assumption that $\mathrm{CH}$ leaching generates capillary pores and C-S-H leaching causes gel pores and capillary pores [3], the diffusivity and permeability increase continuously. The increased permeability coefficient and diffusion coefficient accelerate the leaching process.
2.1. Governing Equations. In the advection-diffusion-driven leaching model, we apply the following six assumptions:

(1) Silicon does not leach at all, and the rehydration and leaching of unhydrated cement particles are ignored either, so only $\mathrm{CH}$ and $\mathrm{C}-\mathrm{S}-\mathrm{H}$ are considered in the leaching process [39];

(2) $\mathrm{CH}$ leaching generates capillary pores, and $\mathrm{C}-\mathrm{S}-\mathrm{H}$ leaching not only causes gel pores but also contributes to capillary pores [3];

(3) Calcium ions in solution are not reacting to form any new compounds [38]

(4) Calcium ions in solution are not reacting to form any new compounds (like $\mathrm{CaCO}_{3}$, for instance) [38]

(5) The materials are and remain saturated over time, and isothermal conditions are preserved [38];

(6) The flow in the capillary pore is laminar, which can be described by Darcy's law

The diffusion equation is suitable for leaching in bridge piers, pile foundations, and nuclear waste containers. For calcium leaching in concrete dam face slabs, concrete core walls, and grout curtains, we should add the $u \nabla c$ to governing equation to express the convection effect of advection flow on calcium ions. $u$ is the Darcy velocity, $c$ is the calcium ion concentration in the pore solution, and $\nabla c$ is the concentration gradient. $u \nabla c$ is the intensity of advection flow, and the physical meaning of $u \nabla c$ is the quantity of calcium ion pass-through per unit area per unit time under advection flow. The advection flow rate is not invariant; with increasing porosity and permeability, the flow rate changes with redistribution of the water pressure. Therefore, the seepage continuity equation is necessary for expressing the evolution of the seepage field. Equation (2) presents the governing equation describing the fluid flow $[40,41]$ and calcium ion dispersion [42] in the permeable porous medium.

$$
\left\{\begin{array}{l}
u=-\frac{k}{\rho g} \nabla P, \\
\frac{\partial\left(\varepsilon_{p} \rho\right)}{\partial t}+\nabla(\rho u)=Q_{m}, \\
\frac{\partial c}{\partial t}+\nabla(-D \nabla c)+u \nabla c=R .
\end{array}\right.
$$

In this equation, $u$ is the Darcy velocity $(\mathrm{m} / \mathrm{s}), k$ is the permeability of the cement-based materials $\left(\mathrm{m}^{2}\right), \rho$ is the water density $\left(\mathrm{kg} / \mathrm{m}^{3}\right), g$ is the gravitational acceleration $(\mathrm{m} /$ $\left.\mathrm{s}^{2}\right), P$ is the water pressure $(\mathrm{Pa}), \varepsilon_{p}$ is the porosity, $t$ is the time (s), $Q_{m}$ is a mass source term $\left(\mathrm{kg} /\left(\mathrm{m}^{3} \cdot \mathrm{s}\right)\right), c$ is the concentration of the species $\left(\mathrm{mol} / \mathrm{m}^{3}\right.$ ) (in this study, $c$ is the concentration of calcium ions in the pore solution), $D$ denotes the diffusion coefficient $\left(\mathrm{m}^{2} / \mathrm{s}\right)$, and $R$ is the calcium compounds decomposition reaction rate $\left(\mathrm{mol} /\left(\mathrm{m}^{3} \cdot \mathrm{s}\right)\right)$.

In this study, retardation factor $R$ refers to the decomposition rate of calcium compounds in the solid skeleton. The decomposition of calcium compound is assumed 


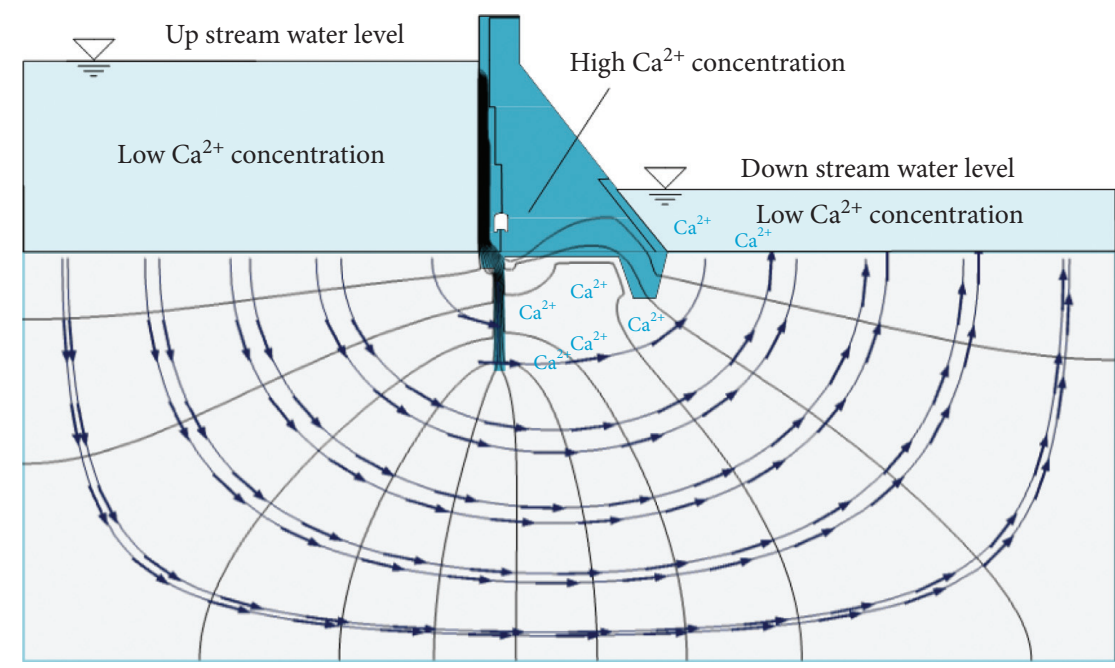

FIGURE 1: General sketch of the physical model for calcium leaching in concrete gravity dam.

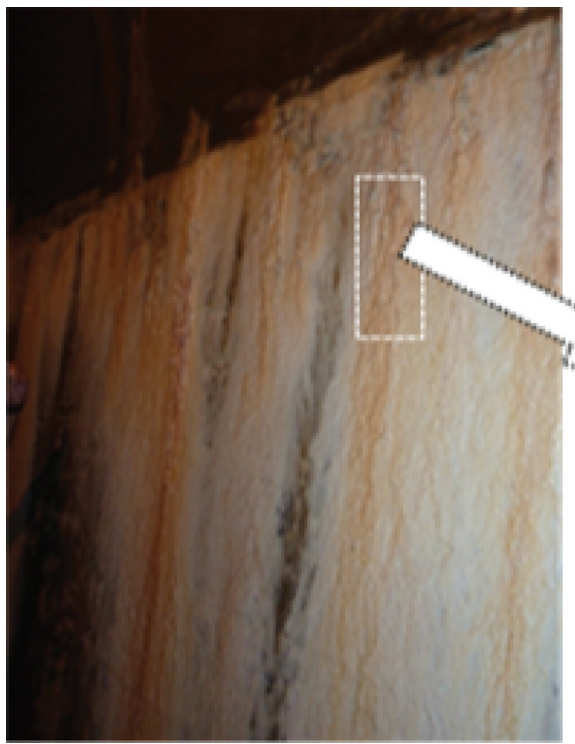

(a)

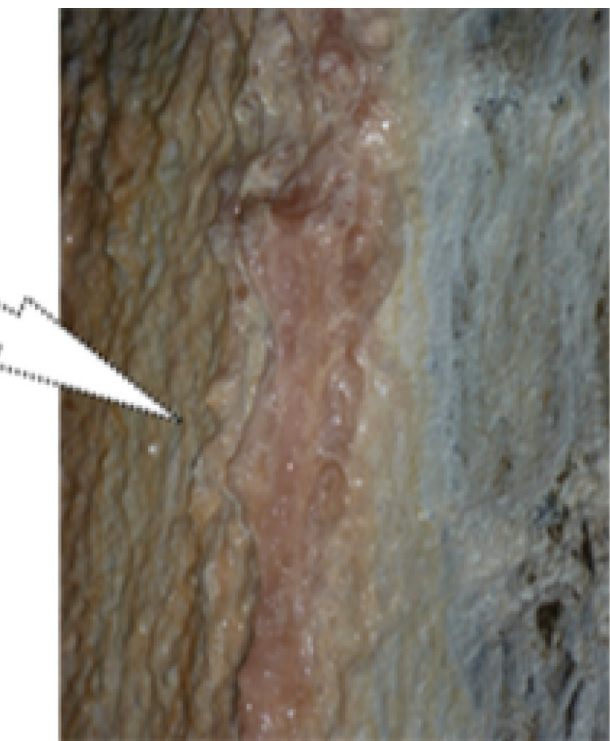

(b)

FiguRe 2: Advection-diffusion-driven leaching in corridors of the Shimantan concrete gravity dam overflow sections. (a) Leached calcium deposited on the surface of corridors. (b) More extensive version of leached calcium, and the main content is calcium carbonate.

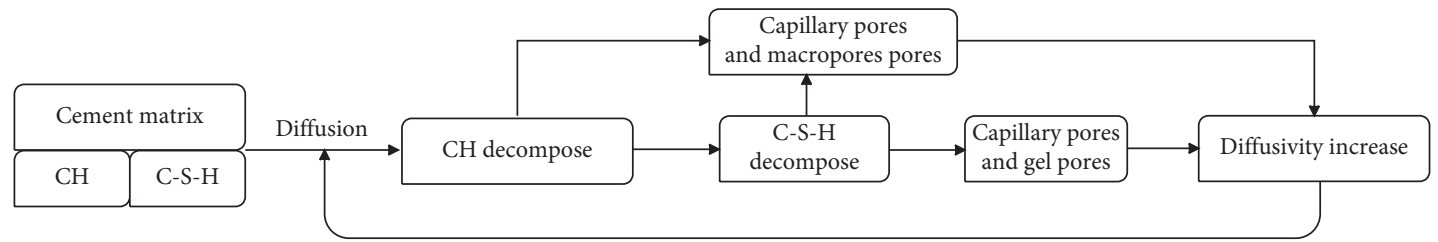

(a)

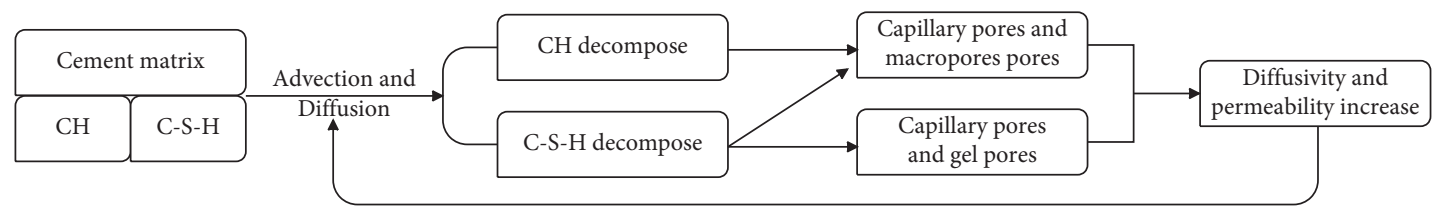

(b)

FIgURE 3: Phenomena of the calcium leaching process under equilibrium and nonequilibrium conditions. (a) Calcium leaching in solidliquid equilibrium condition. (b) Calcium leaching in solid-liquid nonequilibrium condition. 
to be an irreversible process under advection-diffusiondriven leaching. In other words, the calcium ion concentration of the solid skeleton will not increase. In practice, calcium ion in the pore solution is nonconservative and can be adsorbed onto the soil particles. The adsorption and chemical reactions that might occur in the soils or rocks are complex. According to Gerard's work [38], calcium ions in solution assume not reacting to other compounds. In this study, considering the enormous scope of the model, the effect of adsorption and chemical reaction in the soils or rocks is assumed to be limited. Therefore, to simplify the numerical model, calcium ions in solution are deemed not to react to form any new compounds, like $\mathrm{CaCO}_{3}$ [38].

The calcium leaching of cement-based material contains two processes. The first stage is the decomposition of calcium compounds, and the second one is the migration of calcium ions in the porous media. Because of the calcium compounds decomposition, the hydraulic conductivity keeps changing in the leaching process. As a result, the flow rate changed. Compared with the existing diffusion-driven leaching, another assumption is needed. Since calcium leaching is a relatively slow process, the water flow in the porous media is still Darcy flow. In this way, Darcy's law determined the flow rate.

2.2. Calcium Compounds Decomposition Model. In the diffusion-driven calcium leaching process, the time required to dissolve $\mathrm{CH}$ and $\mathrm{C}-\mathrm{S}-\mathrm{H}$ is shorter than the diffusion time [38]. As a result, there is an equilibrium state between calcium compounds and calcium ions. Buil and Berner first proposed the solid-liquid equilibrium curve in 1992 [43]. Equation (3) is a typical solid-liquid equilibrium curve modified by Nakarai [15].

$$
\frac{\partial s_{\mathrm{Ca}}}{\partial c}= \begin{cases}\left(-\frac{2}{x_{1}^{3}} c^{3}+\frac{3}{x_{1}^{2}} c^{2}\right)\left\{C_{\mathrm{CSH} 0}\left(\frac{c}{c_{\text {satu }}}\right)^{1 / 3}\right\}, & 0 \leq c \leq x_{1}, \\ \left\{C_{\mathrm{CSH} 0}\left(\frac{c}{c_{\text {satu }}}\right)^{1 / 3}\right\}, & x_{1} \leq c \leq x_{2}, \\ \left\{C_{\mathrm{CSH} 0}\left(\frac{c}{c_{\text {satu }}}\right)^{1 / 3}\right\}+\frac{C_{\mathrm{CH} 0}}{\left(c_{\text {satu }}-x_{2}\right)^{3}}, & \left(c-x_{2}\right)^{3} x_{2} \leq c,\end{cases}
$$

where $s_{\mathrm{Ca}}$ is the actual calcium concentration in the solid skeleton $\left(\mathrm{mol} / \mathrm{m}^{3}\right), c$ is the concentration of calcium ions in the pore solution $\left(\mathrm{mol} / \mathrm{m}^{3}\right), x_{1}$ is the calcium ion concentration in the pore solution when sharp decomposition of C-S-H starts $\left(\mathrm{mol} / \mathrm{m}^{3}\right), x_{2}$ is the calcium ion concentration in the pore solution when $\mathrm{CH}$ is completely dissolved and C-S-H starts to decompose $\left(\mathrm{mol} / \mathrm{m}^{3}\right), c_{\text {satu }}$ is the saturation concentration in deionized water at room temperature ( $\mathrm{mol} /$ $\left.\mathrm{m}^{3}\right), C_{\mathrm{CSH} 0}$ and $\mathrm{C}_{\mathrm{CH} 0}$ are the nonleached C-S-H gel and $\mathrm{CH}$ content, respectively, which can be calculated from the cement chemical composition $\left(\mathrm{mol} / \mathrm{m}^{3}\right), x_{1}$ is taken as $2 \mathrm{~mol} / \mathrm{m}^{3}$ by Gerard [44], Wan [39], Nakarai [15], and Jain [45], $x_{2}$ is taken as $\left(c_{\text {satu }}-3\right) \mathrm{mol} / \mathrm{m}^{3}$ by Wan [39], Nakarai
[15], and Phung [3], or $\left(c_{\text {satu }}-1\right) \mathrm{mol} / \mathrm{m}^{3}$ by Gerard [44], Jain [45], and $c_{\text {satu }}$ is taken as $22 \mathrm{~mol} / \mathrm{m}^{3}$ by Phung [3], Jain [45], and Wan [43] or $20 \mathrm{~mol} / \mathrm{m}^{3}$ by Gerard [45] and Kuhl [20], or $20.5 \mathrm{~mol} / \mathrm{m}^{3}$ by Gawin [34]. In this study, the value of $x_{1}, x_{2}$, and $c_{\text {satu }}$ are taken as 2,19 , and $22 \mathrm{~mol} / \mathrm{m}^{3}$. According to Allen's test [18] and Jennings' work [19], the initial $\mathrm{Ca} / \mathrm{Si}$ ratio of $\mathrm{C}-\mathrm{S}-\mathrm{H}$ is 1.70 , and the $\mathrm{Ca} / \mathrm{Si}$ ratio of partially leached C-S-H is 0.8 .

The solid-liquid equilibrium curve provides a relationship between calcium ion concentration in pore solution and calcium compounds in the solid skeleton, which is suitable for the locally diffusion-controlled reaction. One of the most critical assumptions of the solid-liquid equilibrium curve is the time required to dissolve the calcium compounds in the solid skeleton shorter than the diffusion time [33, 38]. However, in advection-diffusion-driven leaching, the calcium ion concentration in the pore solution may be lower than the equilibrium concentration. The calcium ion in the pore solution is no longer in an equilibrium state with calcium compounds in the solid skeleton. Under the migration effect of advection flow, calcium compounds leaching time in the solid skeleton is no longer faster than the diffusion time. Therefore, the solid-liquid equilibrium curve is not suitable for advection-diffusion-driven leaching.

Ulm et al. [33] proposed a nonequilibrium decomposition model of calcium compounds using chemoporoplasticity theory. Gawin [36] neglected the elastic deformation and plastic hardening-softening phenomena term and the decomposition rate presented in the following equation:

$$
\left\{\begin{aligned}
\frac{\partial s_{\mathrm{Ca}}}{\partial t} & =\frac{1}{\eta} A_{s}, \\
\eta & =\mathrm{RT} \tau_{\text {leach }}, \\
A_{s} & =\mathrm{RT} \ln \left(\frac{c_{\mathrm{Ca}}}{c_{\mathrm{Ca}}^{\mathrm{eq}}}\right)-\int_{S_{\mathrm{Ca}}^{\mathrm{eq}}}^{s_{\mathrm{Ca}}} \kappa(\bar{s}) \mathrm{d} \bar{s}, \\
\kappa\left(s_{\mathrm{Ca}}\right) & =\frac{\mathrm{RT}}{c_{\mathrm{Ca}}}\left(\frac{\mathrm{d} s_{\mathrm{Ca}}}{\mathrm{d} c_{\mathrm{Ca}}}\right)^{-1},
\end{aligned}\right.
$$

where $s_{\mathrm{Ca}}$ is the actual calcium concentration in the solid skeleton $\left(\mathrm{mol} / \mathrm{m}^{3}\right), t$ is the time (s), $\eta$ is the microdiffusion of $\mathrm{Ca}^{2+}$ ions in different compounds, which is dependent on the calcium content $(\mathrm{mol} /(\mathrm{J} \cdot \mathrm{s})), A_{s}$ is the chemical affinity, being a driving force of chemical reactions $\left(\mathrm{J} / \mathrm{m}^{3}\right), R$ is the gas constant $(\mathrm{J} /(\mathrm{mol} \cdot \mathrm{K})), T$ is the temperature $(\mathrm{K}), \tau_{\text {leach }}$ is the characteristic time of leaching $(s), c_{\mathrm{Ca}}$ is the present calcium concentration in the pore solution $\left(\mathrm{mol} / \mathrm{m}^{3}\right),\left(c_{\mathrm{Ca}}^{\mathrm{eq}}\right.$, $\left.s_{\mathrm{Ca}}^{\mathrm{eq}}\right)$ is a point on the solid-liquid equilibrium curve, and $\kappa\left(s_{\mathrm{Ca}}\right)$ is the equilibrium constant.

$A_{s}$ in equation (4) is not convenient to be used in simulations because it requires knowledge of the pair of values $\left(c_{\mathrm{Ca}}^{\mathrm{eq}}, s_{\mathrm{Ca}}^{\mathrm{eq}}\right)$. Gawin [36] transferred this equation into a form which is more suitable for practical applications as in the following equation: 


$$
A_{s}=\int_{S_{\mathrm{Ca}}^{0}}^{s_{\mathrm{Ca}}^{*}} \kappa\left(s_{\mathrm{Ca}}\right) \mathrm{d} s_{\mathrm{Ca}}-\int_{S_{\mathrm{Ca}}^{0}}^{S_{\mathrm{Ca}}} \kappa\left(s_{\mathrm{Ca}}\right) \mathrm{d} s_{\mathrm{Ca}},
$$

where $s_{\mathrm{Ca}}^{0}$ is the initial calcium concentration in the solid skeleton $\left(\mathrm{mol} / \mathrm{m}^{3}\right), s_{\mathrm{Ca}}$ is the actual calcium concentration in the solid skeleton $\left(\mathrm{mol} / \mathrm{m}^{3}\right), s_{\mathrm{Ca}}^{*}$ is the equilibrium value corresponding to current calcium concentration in the pore solution $\left(\mathrm{mol} / \mathrm{m}^{3}\right)$, and $s_{\mathrm{Ca}}^{*}$ can be calculated by equation (3).

Figure 4(a) shows the solid-liquid equilibrium curve with different $\mathrm{CH}$ content and equilibrium $\int_{S_{\mathrm{Ca}}^{*}}^{S_{\mathrm{C}}} \kappa(\bar{s}) \mathrm{d} \bar{s}$ at temperature $T=25$. The $\mathrm{CH}$ content is defined as $\mathrm{C}_{\mathrm{CH}} /\left(C_{\mathrm{CH}}+C_{\mathrm{CSH}}\right)$. The total calcium compound in the solid skeleton is $15,000 \mathrm{~mol} / \mathrm{m}^{3}$. The solid-liquid equilibrium curve is calculated with equation (3). As we can see from Figure 4(a), the $\mathrm{CH}$ decomposition stage becomes shorter as $\mathrm{CH}$ content decreases. Figure $4(\mathrm{~b})$ shows $\int_{S_{\mathrm{C}}^{*}}^{S_{\mathrm{Ca}}} \kappa(\bar{s}) \mathrm{d} \bar{s}$ as a function of the calcium content, and the temperature $T$ is 25 .

Taking the actual "distance" from the equilibrium curve as the measurement of calcium compounds decomposition rate is suitable for advection-diffusion-driven leaching. In advection-diffusion-driven leaching, advection flow carries the calcium ions in the pore solution out. As a result, the calcium ion concentration in the pore solution is always lower than in the equilibrium stage. Therefore, we should not calculate the calcium compounds in the solid skeleton from calcium ion concentration in the pore solution with equation (4). Under this circumstance, we can calculate the calcium compound content by integrating the decomposition rate with time.

The driven force of calcium leaching determines the model used in the simulation. For diffusion-driven leaching, we should use the solid-liquid equilibrium model. While for advection-diffusion-driven leaching, we should use the nonequilibrium model. The dimensionless Péclet number (Pe number) represents the relative proportion of advection and diffusion. Pe number is defined as in the following equation [46].

$$
\mathrm{Pe}=\frac{u R}{D_{e}},
$$

where $u$ is the mean flow velocity in the porous media $(\mathrm{m} / \mathrm{s})$, $R$ is the characteristic length, for cement-based material, and $R$ is the average diameter of particles [47]. According to the code for mix design of hydraulic concrete (DL/T 5330-2015), the average diameters of two-grade roller-compacted concrete, three-grade compacted concrete, and regular concrete are $0.02 \mathrm{~m}, 0.04 \mathrm{~m}$, and $0.02 \mathrm{~m}$. This study takes the average diameter of grout curtain as $0.01 \mathrm{~m}$. $D_{e}$ is the molecular diffusion, $\mathrm{m}^{2} / \mathrm{s}$. When Pe number is less than 1 , diffusion is dominant. When Pe number is more than 100 , the effect of diffusion can be ignored [48].

2.3. Porosity Evolution. The main calcium compound content in cement-based materials includes $\mathrm{CH}$ and $\mathrm{C}-\mathrm{S}-\mathrm{H}$. Wan [39] assumed that $\mathrm{CH}$ leaching generates capillary pores and that $\mathrm{C}-\mathrm{S}-\mathrm{H}$ leaching generates gel pores. In contrast, Phung [3] proposed that decalcification of C-S-H may also contribute to the increase in capillary porosity due to the spatial connectivity of gel pores. Kuhl [20] proposed a simplified model for calculating porosity with an average molar volume of $\mathrm{CH}$, ettringite, and $\mathrm{C}-\mathrm{S}-\mathrm{H}$. By integrating the decomposition rate of calcium compounds, we can obtain the total molar amount of dissolved calcium compounds and porosity. The method was adopted by Gawin [36]. The main disadvantage of this method is that it ignores the effect of different calcium compound decomposition on pore growth.

To more accurately calculate the evolution of porosity and permeability coefficient of materials, we should consider the influence of the decomposition of $\mathrm{CH}$ and $\mathrm{C}-\mathrm{S}-\mathrm{H}$ on the porosity. The porosity evolution of cement-based materials is shown in the following equations.

$$
\begin{aligned}
& \left\{\begin{array}{l}
\varphi=\varphi_{0}+\Delta \varphi_{\mathrm{CH}}+\Delta \varphi_{\mathrm{CSH}} \\
\varphi_{c}=\varphi_{c 0}+\Delta \varphi_{\mathrm{CH}}+\gamma \Delta \varphi_{\mathrm{CSH}}
\end{array}\right. \\
& \left\{\begin{array}{l}
\Delta \varphi_{\mathrm{CH}}=\int \frac{1}{\eta_{\mathrm{CH}} V_{\mathrm{CH}}} A_{s} \mathrm{~d} t \\
\Delta \varphi_{\mathrm{CSH}}=\int \frac{1}{\eta_{\mathrm{CSH}} V_{\mathrm{CSH}}} A_{s} \mathrm{~d} t
\end{array}\right.
\end{aligned}
$$

where $\varphi$ is the total porosity, $\varphi_{0}$ is the initial porosity, $\Delta \varphi_{\mathrm{CH}}$ is the porosity increase due to $\mathrm{CH}$ decomposition, $\Delta \varphi_{\mathrm{CSH}}$ is the porosity increase due to $\mathrm{C}-\mathrm{S}-\mathrm{H}$ decomposition, $\varphi_{\mathrm{c}}$ is the capillary porosity, $\varphi_{\mathrm{c} 0}$ is the initial capillary porosity, and $\gamma$ is the extent of contribution of C-S-H decalcification to capillary porosity; in this study, $\gamma=0.5[3], V_{\mathrm{CH}}$ and $V_{\mathrm{CSH}}$ are the molar volume of $\mathrm{CH}$ and $\mathrm{C}-\mathrm{S}-\mathrm{H}$, $V_{\mathrm{CH}}=0.033 \times 10^{-6} \mathrm{~mol} / \mathrm{m}^{3}, \quad V_{\mathrm{CSH}}=0.04 \times 10^{-3} \mathrm{~mol} / \mathrm{m}^{3}$, $\eta_{\mathrm{CH}}$ and $\eta_{\mathrm{CSH}}$ are the coefficients related to the microdiffusion of $\mathrm{Ca}^{2+}$ ions in $\mathrm{CH}$ and C-S-H, and the values of $\eta_{\mathrm{CH}}$ and $\eta_{\mathrm{CSH}}$ are given in Table 1 .

In advection-diffusion-driven leaching, when the calcium ion concentration in the pore solution is between 19 and $22 \mathrm{~mol} / \mathrm{m}^{3}, \mathrm{CH}$ decomposes. When the ion concentration is below $19 \mathrm{~mol} / \mathrm{m}^{3}, \mathrm{CH}$ and C-S-H decompose simultaneously, combined with equations (4) and (5), and the porosity increase induced by decomposition of $\mathrm{CH}$ and C-S$\mathrm{H}$ can be obtained, respectively. According to Morandeau's experimental data [49], the molar volume of C-S-H is linear with the ratio of $\mathrm{Ca} / \mathrm{Si}$ ratio. In this study, we also considered the dependence of the molar volume of $\mathrm{C}-\mathrm{S}-\mathrm{H}$ on $\mathrm{Ca} / \mathrm{Si}$. Therefore, the molar volume of C-S-H in the leaching process is defined as a function of $\mathrm{Ca} / \mathrm{Si}$. More details are presented in Appendix A.

2.4. Permeability Evolution. During the leaching of cementbased materials, the intrinsic permeability $\mathrm{K}$ may increase significantly due to skeleton decalcification and is related to the leaching-induced porosity increase. Saito [50] proposed an exponential formula between porosity and permeability, and the relation presents in equation (8).

$$
K=K\left(n_{0}\right) 10^{A_{T} n},
$$




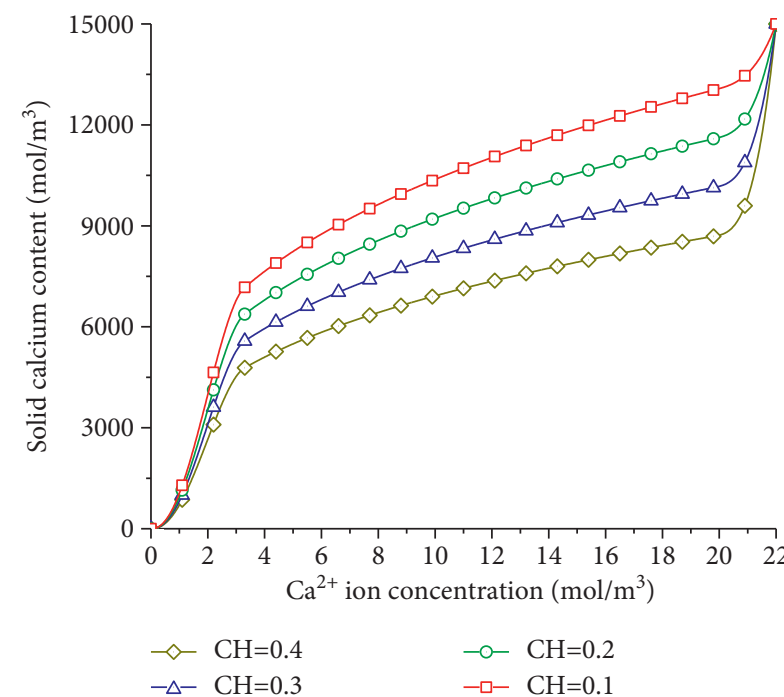

(a)

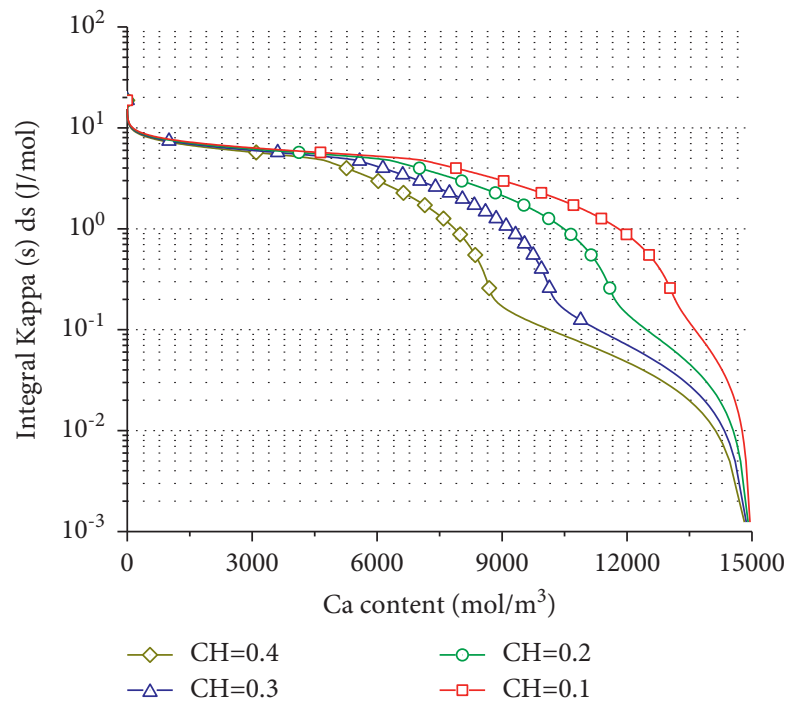

(b)

FIgURE 4: (a) Solid-liquid equilibrium curve with different $\mathrm{CH}$ contents. (b) $\int_{S_{\mathrm{Ca}}^{*}}^{S_{\mathrm{Ca}}} \kappa(\bar{s}) \mathrm{d} \bar{s}$ as a function of the calcium content.

TABLE 1: Values of the nonequilibrium decomposition model of calcium compounds [25].

\begin{tabular}{lccccc}
\hline Skeleton compound & $\mathrm{Ca}^{2+}$ concentration $\left(\mathrm{mol} / \mathrm{m}^{3}\right)$ & $\mathrm{d} s_{\mathrm{Ca}} / \mathrm{d} c_{\mathrm{Ca}}$ & Diffusivity $\left(\mathrm{m}^{2} / \mathrm{s}\right)$ & $\tau_{\text {leach }}(\mathrm{s})$ & $1 / \eta(\mathrm{mol} /(\mathrm{J} \cdot \mathrm{s}))$ \\
\hline $\mathrm{CH}$ & $19-22$ & 2142 & $1.44 \times 10^{-9}$ & $1.17 \times 10^{4}$ & $3.45 \times 10^{-8}$ \\
C-S-H & $2-19$ & 203 & $1.62 \times 10^{-9}$ & $5.88 \times 10^{2}$ & $0.7 \times 10^{-8}$ \\
C-S-H & $0-2$ & 1910 & $1.83 \times 10^{-9}$ & $6.52 \times 10^{3}$ & $6.2 \times 10^{-8}$ \\
\hline
\end{tabular}

where $K\left(n_{0}\right)$ is the initial permeability $(\mathrm{m} / \mathrm{s}), A_{T}$ is a material parameter that should be determined experimentally, and $n$ is the concrete porosity.

This equation works well in accelerated electrochemical tests on mortars. However, to better understand the leaching effect on the increase in cement-based material permeability, it is necessary to explore the evolution of microstructure parameters. The Kozeny-Carman (KC) relation works well for relatively homogeneous porous materials [51-53]. The permeability coefficient presents in the following equation.

$$
\left\{\begin{array}{l}
K=\chi \frac{\varphi^{3}}{(1-\varphi)^{2}}, \\
\chi=\frac{1}{\tau^{2} S_{a}^{2} F_{s}},
\end{array}\right.
$$

where $K$ is the permeability coefficient $\left(\mathrm{m}^{2}\right), \chi$ is the microstructure parameter $\left(\mathrm{m}^{2}\right), \varphi$ is the capillary porosity, $\tau$ is the tortuosity, $S_{a}$ is the specific pore surface $\left(\mathrm{m}^{2} / \mathrm{m}^{3}\right)$, and $F_{s}$ is the shape factor.

The permeability is defined as a function of porosity in equation (8), neglecting the influence of pore structure evolution on permeability. The variables related to pore structure are included in the parameter $A_{T}$. The Kozeny-Carman relation considered porosity and pore structures such as tortuosity, specific pore surface, and shape factor on the permeability evolution. In this way, the modelling of permeability evolution is more accurate. More details of this equation presented in Appendix B.

2.5. Diffusivity Evolution. In the process of calcium leaching, the diffusivity also increases with the porosity [54-57]. Garboczi and Bentz [8] proposed the effective diffusion model. We can calculate the effective diffusivity of cement paste from cement hydration and the water-cement ratio. Garboczi and Bentz's model holds for a standard nonleached cement matrix. In the leaching process, the diffusivity increases much more rapidly. Based on Snyder and Clifton's work, van Eijk and Brouwers [58] proposed a revised formula as in the following equation.

$$
\begin{aligned}
\frac{D_{e}}{D_{0}}= & 0.0025-0.07 \varphi_{c}(x, 0)^{2} \\
& -1.8 H\left(\varphi_{c}(x, 0)-0.18\right)\left(\varphi_{c}(x, 0)-0.18\right)^{2} \\
& +0.14 \varphi_{c}(x, t)^{2} \\
& +3.6 H\left(\varphi_{c}(x, t)-0.16\right)\left(\varphi_{c}(x, t)-0.16\right)^{2}=D(\varphi)
\end{aligned}
$$

where $\varphi_{c}(x, 0)$ is the initial capillary porosity, $H$ is the Heaviside function, $\varphi_{c}(x, t)$ is the capillary porosity, and $D_{0}$ is the diffusivity of $\mathrm{Ca}$ ion in water, $D_{0}=4.5 \times 10^{-10} \mathrm{~m}^{2} / \mathrm{s}$. 
Equation (11) has been widely used in calcium leaching simulations, such as Wan [39]. In this study, we adopt this equation to modelling the evolution of the diffusion coefficient in the leaching process.

\subsection{Overall Scheme of the Advection-Diffusion-Driven} Leaching Model. In advection-diffusion-driven leaching, the decomposition rate of calcium compounds is a function of calcium ion concentration in the pore solution and current calcium content in the solid skeleton. Under the convection effect of advection and diffusion, the distribution of calcium ion concentration varies with distance and time. Therefore, the decomposition rates of different dam structures are not the same. We can calculate the quantity of decomposed calcium compounds from the integral decomposition rate with time. Once the decomposed calcium amount is determined, the porosities, hydraulic conductivities, and diffusivities are obtained. Due to the evolution of hydraulic conductivity and diffusivity, the calcium ion concentration of the pore solution redistributes. In this study, the calcium ion concentration, decomposition rate of calcium compounds, porosity, hydraulic conductivity, and diffusivity varied with distance and time.

Figure 5 shows the overall framework of this model. First of all, input the geometric model, material properties, and solution conditions. We can obtain the concentration of calcium ion in pore solution by solving the advection-diffusion equation and seepage continuity equation. Combining with the solid-liquid nonequilibrium model, the decomposition rate of the solid phase is available. By integrating the decomposition rate of calcium compounds with time, the amount of leached and remained calcium compounds are obtained. After that, we can calculate the porosity. The permeability and diffusivity are defined as functions of porosity. Therefore, the advection flow rate and calcium ion diffusivity coefficient are obtained. At this moment, the seepage characteristic is changed under the effect of calcium leaching. The advection-diffusion equation and seepage continuity equation need to be solved again. The calcium concentration is redistributed under the impact of changed advection flow rate and calcium ion diffusivity coefficient. In this study, we numerically solve the problem using the COMSOL Multiphysics simulation tool. The finite element method has been adopted.

\section{Numerical Example}

A numerical example is solved to compare this study and previous studies to validate the proposed model. This example is a fast reaction-advection-diffusion problem solved previously by Gawin et al. [34, 35]. It concerns calcium leaching from a cement paste wall (1D problem) exposed to one-side action of deionized water, which is modelled with Dirichlet boundary conditions. The model configuration and boundary conditions are shown in Figure 6. The primary materials' properties are given in Table 2. More details are present in reference [35].

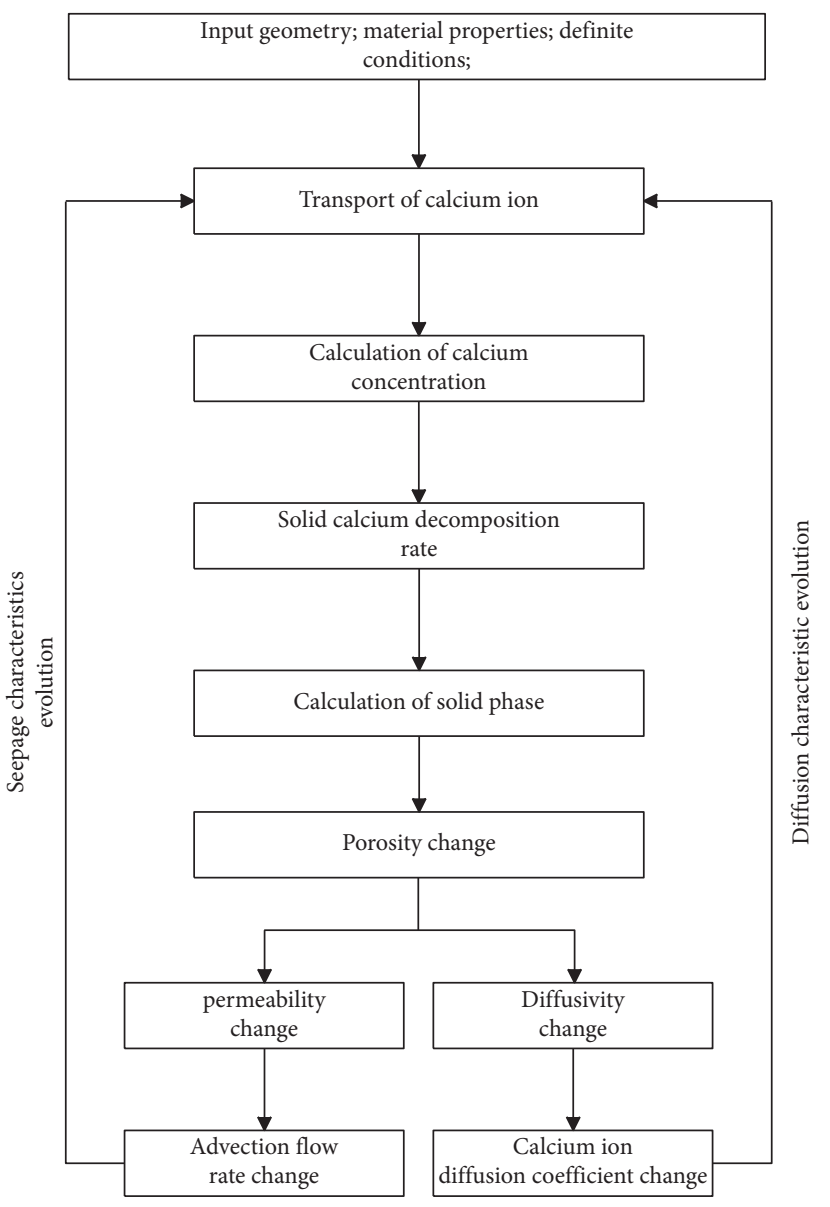

Figure 5: Overall scheme of the leaching model.

The time history of calcium ion concentration in pore solution and space distributions at different time stations are shown in Figure 7. The simulation results are obtained from the proposed model with and without different calcium compounds decomposition effects. Reference points 1 and 2 are $0.09 \mathrm{~cm}$ and $2.88 \mathrm{~cm}$ from the upstream side, respectively. The leaching duration is $2 \times 10^{8} \mathrm{~s}$ and $6 \times 10^{8} \mathrm{~s}$. The boundary conditions and material properties used in this simulation are the same as Gawin's Case 4. The simulation results of this study are consistent with Gawin's results [35], which indicate the rationality of this simulation. However, the time history of calcium ion concentration considering different calcium compound decomposition is larger. This is because the proposed model removed the effect of gel pores produced by C-S-H decomposition on transport properties.

Figure 8 shows the time history of hydraulic conductivity and its space distributions at different time stations. As we can see from Figure 8(a), the time history of hydraulic conductivity considering different calcium compounds decomposition is lower. Figure 8(b) shows that within the range of $0.04 \mathrm{~m}$ from the upstream side, the hydraulic conductivity without considering different components is one order of magnitude larger than that considered. In the previous model, the pores generated by C-S-H decomposition are all considered capillary pores. In the proposed model, we have taken the effect of different calcium 


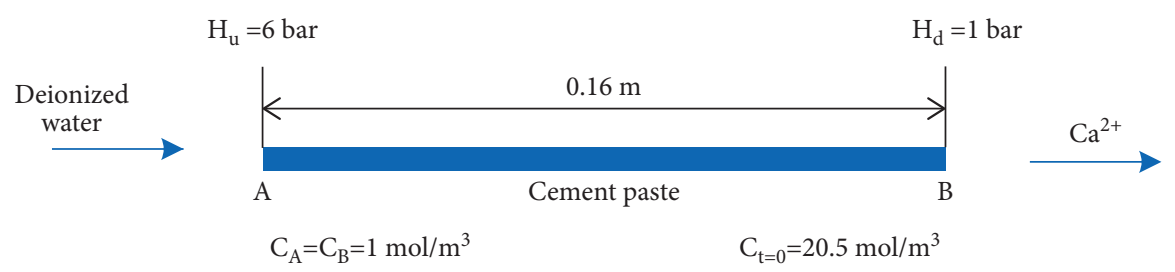

Figure 6: Model configuration and boundary conditions.

TABLE 2: Main material properties assumed in Gawin's simulation [35].

\begin{tabular}{lccc}
\hline Material properties & Symbol & Unit & Cement paste \\
\hline Water/cement ratio & $\mathrm{w} / \mathrm{c}$ & $(-)$ & 0.5 \\
Initial porosity & $\mathrm{n}$ & $(\%)$ & 20 \\
Initial permeability & $\mathrm{k}$ & $\left(\mathrm{m}^{2}\right)$ & $0.5 \times 10^{-18}$ \\
Initial diffusivity & $\mathrm{d}$ & $\left(\mathrm{m}^{2}\right)$ & $1.47 \times 10^{-11}$ \\
Ca content in skeleton & $\mathrm{S}$ & $\left(\mathrm{mol} / \mathrm{m}^{3}\right)$ & 15,000 \\
\hline
\end{tabular}

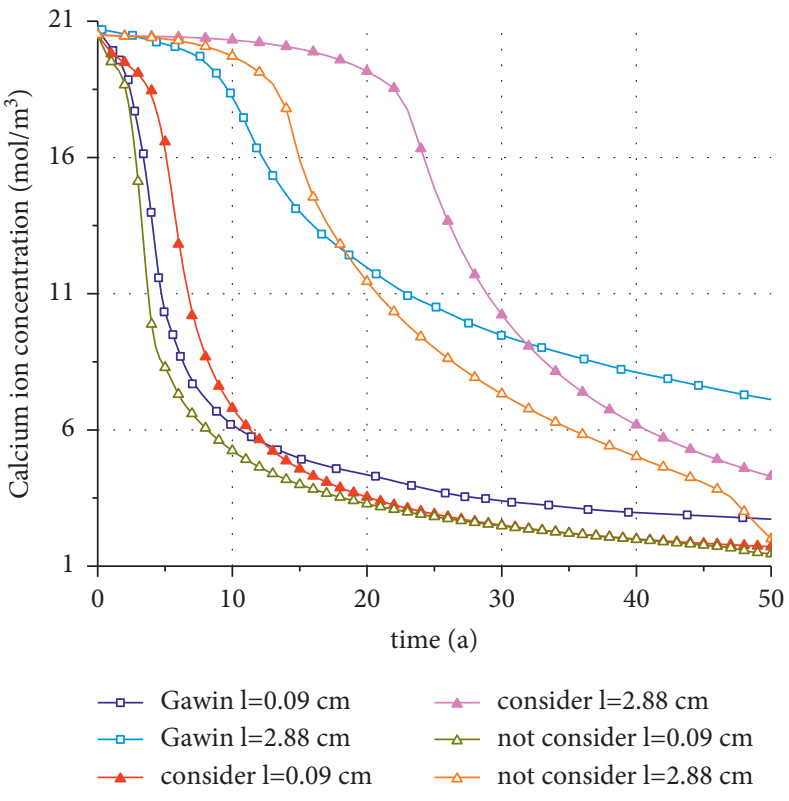

(a)

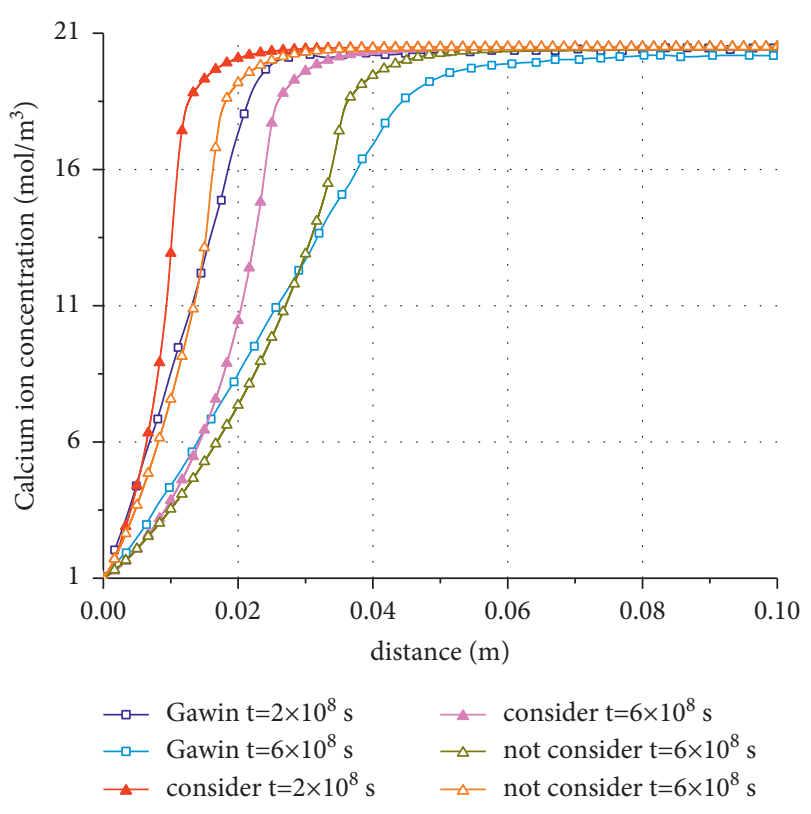

(b)

FIGURE 7: Time history of calcium ion concentration in pore solution and its space distributions at different time stations, obtained from simulations of considered different calcium compounds decomposition effect (solid dot) or not (empty dot) and compared to Gawin's results (empty square). (a) Time history. (b) Space distribution.

compound decomposition on porosity evolution into consideration, $\mathrm{CH}$ leaching generates capillary pores, and $\mathrm{C}-\mathrm{S}-\mathrm{H}$ leaching causes gel pores and capillary pores.

\subsection{Shimantan Concrete Gravity Dam and Numerical Model}

3.1.1. Shimantan Concrete Gravity Dam and Numerical Model. In the middle of China, the Shimantan reservoir, located in Wugang city, first built in 1951, was damaged in flood overtopping accidents in August 1975. The government rebuilt the reservoir in September 1993, and after four years of construction, major structures were finished and accepted by the administration. The critical project of the rebuilt reservoir is a complete roller-compacted concrete (RCC) gravity dam with a height of $40.5 \mathrm{~m}$. The maximum width of the dam body is $31.74 \mathrm{~m}$. The crest length is $645 \mathrm{~m}$ and is divided into 22 dam sections. Among these, Nos. 1-9 and Nos. 17-22 are nonoverflow dam sections, with a total length of $320 \mathrm{~m}$. No. 19 is the bottom hole dam section, with a length of $18 \mathrm{~m}$. The rest are overflow dam sections with a total length of $132 \mathrm{~m}$. The upstream side of the nonoverflow dam section is vertical. On the downstream side, the slope is initially $1: 0.75$ and is then vertical above altitude $103.67 \mathrm{~m}$. In the dam body near the upstream side, there is a grouting and drainage corridor. The bottom altitude is $77.00 \mathrm{~m}$, the cross-section is rectangular with an arch crown, and the width $\times$ height is $2.5 \mathrm{~m} \times 3.0 \mathrm{~m}$. To strengthen the 


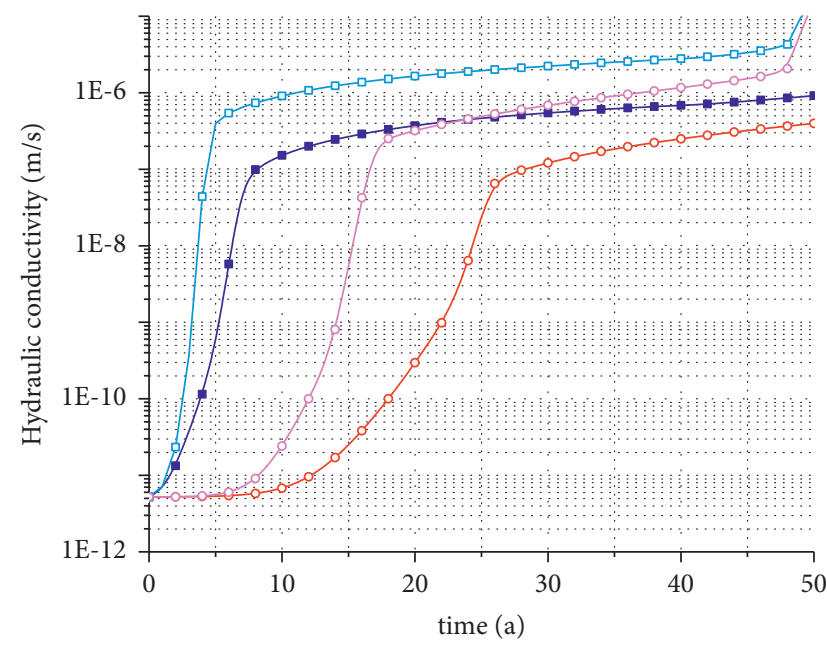

$\rightarrow$ consider $\mathrm{l}=0.96 \mathrm{~cm} \quad \longrightarrow$ not consider $\mathrm{l}=0.96 \mathrm{~cm}$

(a)

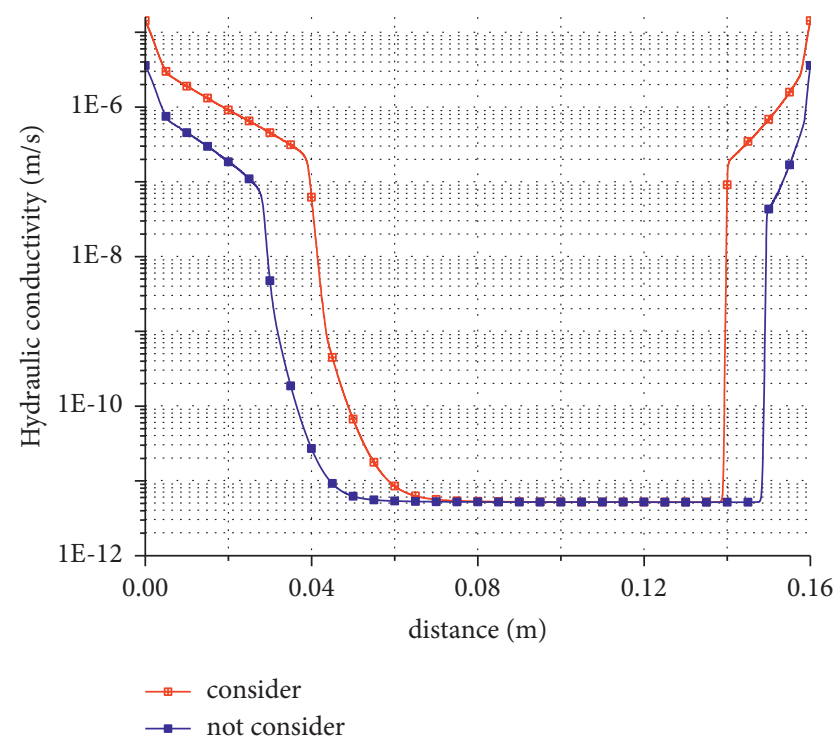

(b)

Figure 8: Time history of hydraulic conductivity and its space distributions at different time stations, obtained from simulations of considered different calcium compounds decomposition effect (solid dot) or not (empty dot). (a) Time history. (b) Space distribution.

antiseepage ability of the dam body, two-grade roller-compacted concrete with a $3 \mathrm{~m}$ thickness was deployed on the upstream side. On the downstream side, below an altitude of $86.00 \mathrm{~m}$, two-grade roller-compacted concrete with a $1.5 \mathrm{~m}$ thickness was deployed. The dam body was made of threegrade roller-compacted concrete. The bed course was made of regular concrete. The geographical location of the Shimantan reservoir is shown in Figure 9. The nonoverflow cross-section of the Shimantan reservoir is shown in Figure 10.

We created a three-dimensional finite element model of Shimantan concrete gravity dam to investigate the seepage characteristic evolution. The model selected the typical nonoverflow dam section. The 3D model of the dam body had six different sections. The concrete face slab is made of two-graded concrete. The maximum thickness of the slab is $4 \mathrm{~m}$, and the minimum thickness is $2 \mathrm{~m}$. The dam body is made of two-graded concrete, and the toothed wall is made of conventional concrete. The thickness of curtain grouting is $2 \mathrm{~m}$, and the depth is $20 \mathrm{~m}$ in bedrock. We simplified the cross-section of the drainage pipe in the dam body and dam foundation as square, and the side length is $0.35 \mathrm{~m}$ and $0.2 \mathrm{~m}$, respectively. We extended the foundation two times the dam's height at both the upstream and downstream sides of the dam. The foundation's height is taken into account as much as two times the dam's height. We simplified the dam body as a homogeneous porous material to reduce the element number. Totally, 653,914 finite elements are used in the $3 \mathrm{D}$ model. The maximum element width is $1.45 \mathrm{~m}$, and the minimum element width is $0.53 \mathrm{~m}$. The finite element meshes of the 3D models are shown in Figure 11.

3.1.2. Calculation Parameters. Since Shimantan concrete gravity dam has been in operation for more than 20 years, it is not easy to obtain the initial parameters of dam materials.
Therefore, the parameters can only be obtained through inverse analysis and experience. The initial permeability coefficients of different material zones are obtained by inverse analysis with monitored data, and empirical parameters determine the initial porosity. The initial diffusivity is calculated from equation (7) with initial porosity. The calcium diffusivity in the water is adopted as the diffusivity in the drain pipe. The initial $\mathrm{CH}$ and $\mathrm{C}-\mathrm{S}-\mathrm{H}$ contents are 6000 and $9000 \mathrm{~mol} / \mathrm{m}^{3}$. Bulk density and initial surface area assume Phung's test parameters of S3 [3], the intact and leached bulk density are $30.6 / 145.8 \mathrm{~m}^{2} / \mathrm{g}$, and the intact and leached surface areas are $1780 / 1110 \mathrm{~kg} / \mathrm{m}^{3}$. The parameters of nonequilibrium solid-liquid dissolution followed Gawin's model. The calculation parameters are given in Tables 1 and 3.

3.1.3. Initial and Boundary Conditions. The initial conditions and boundary conditions are shown in Figure 12.

For the calcium leaching zones, which include normal concrete, two-grade concrete, three-grade concrete, and grout curtain, the pore solution is assumed to be saturated according to the previous studies [3, 39]. The initial calcium ion concentration is assumed to be zero for the nonleaching zones, including the rock layer and drain pipes. The initial calcium concentration is described as in the following equation.

$$
\begin{cases}c(t=0)=22 \mathrm{~mol} / \mathrm{m}^{3}, & \text { leaching zone } \\ c(t=0)=0 \mathrm{~mol} / \mathrm{m}^{3}, & \text { nonleaching zone. }\end{cases}
$$

Upstream water pressure boundary applies on the surface of concrete face slab and reservoir basin below $107 \mathrm{~m}$. Downstream water pressure boundary applies on the surface of the dam body and reservoir basin below the elevation of 
$113^{\circ} 5^{\prime} \mathrm{E} \quad 113^{\circ} 10^{\prime} \mathrm{E} \quad 113^{\circ} 15^{\prime} \mathrm{E} \quad 113^{\circ} 20^{\prime} \mathrm{E} \quad 113^{\circ} 25^{\prime} \mathrm{E} \quad 113^{\circ} 30^{\prime} \mathrm{E} \quad 113^{\circ} 35^{\prime} \mathrm{E} \quad 113^{\circ} 40^{\prime} \mathrm{E} \quad 113^{\circ} 45^{\prime} \mathrm{E} \quad 113^{\circ} 50^{\prime} \mathrm{E} \quad 113^{\circ} 55^{\prime} \mathrm{E}$

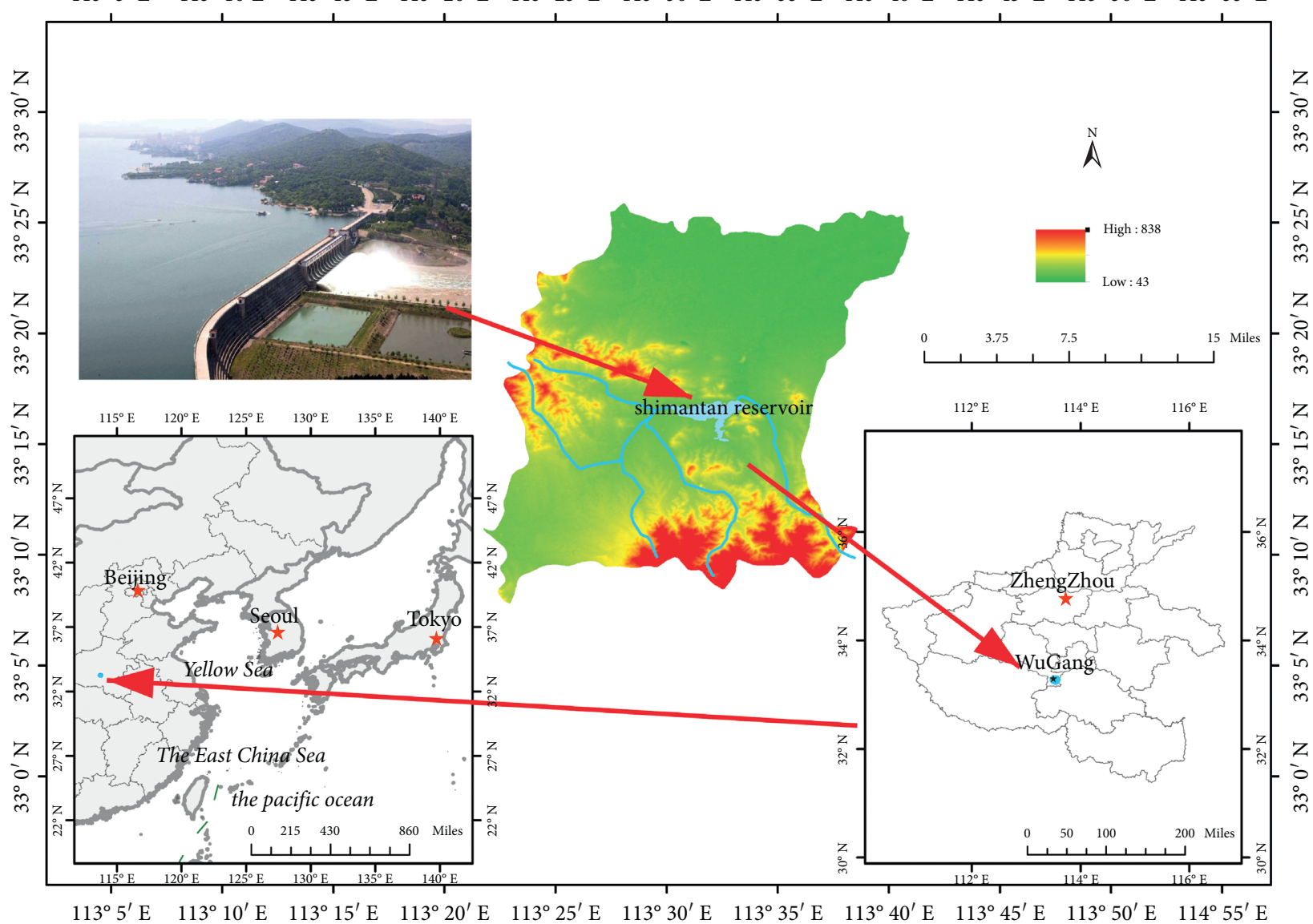

FIgURE 9: Geographical location of the Shimantan reservoir.

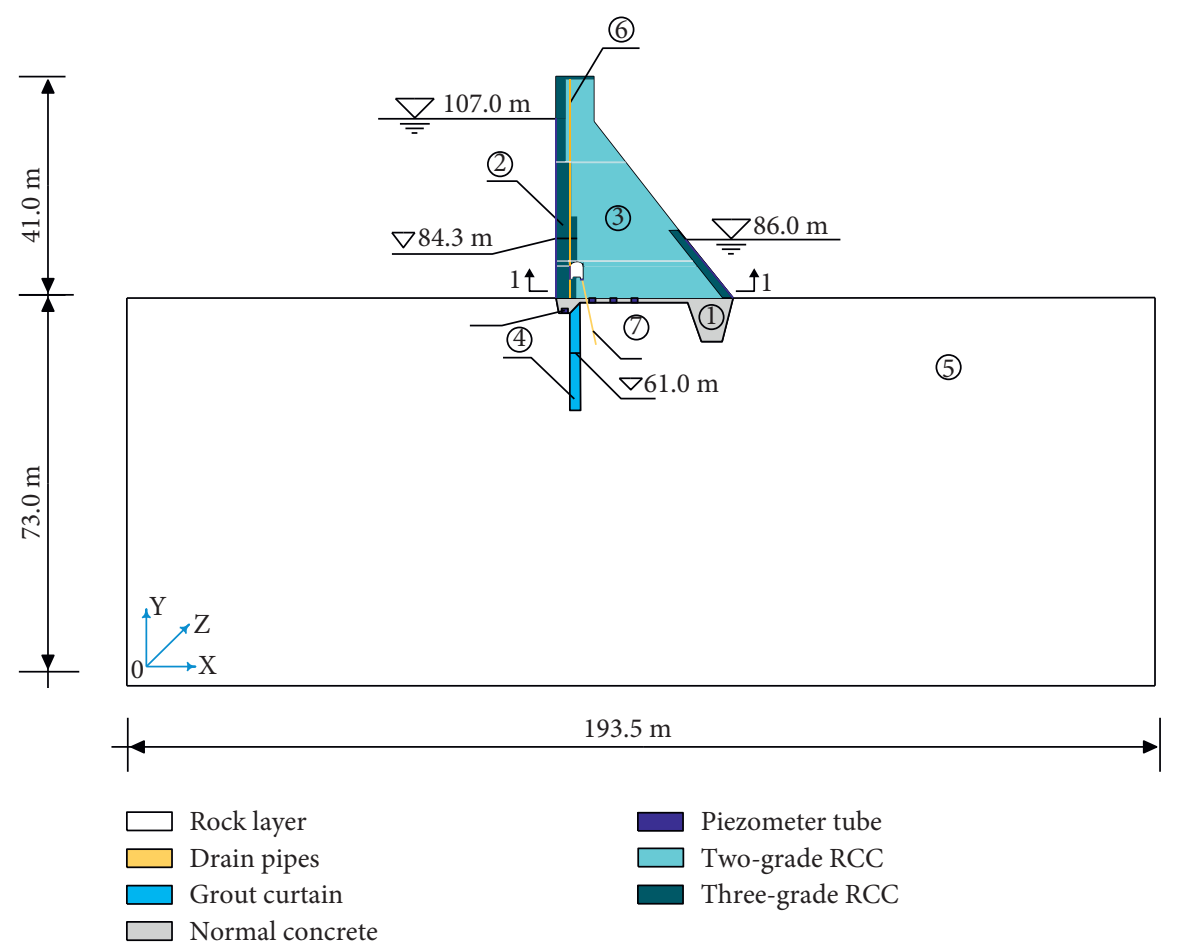

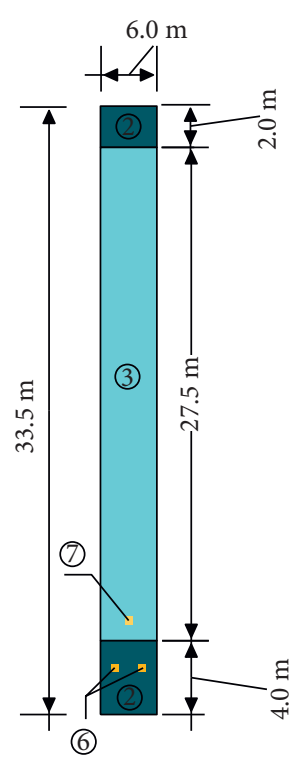

1-1 section

FIGURE 10: Overall layout and profile of the Shimantan reservoir. 


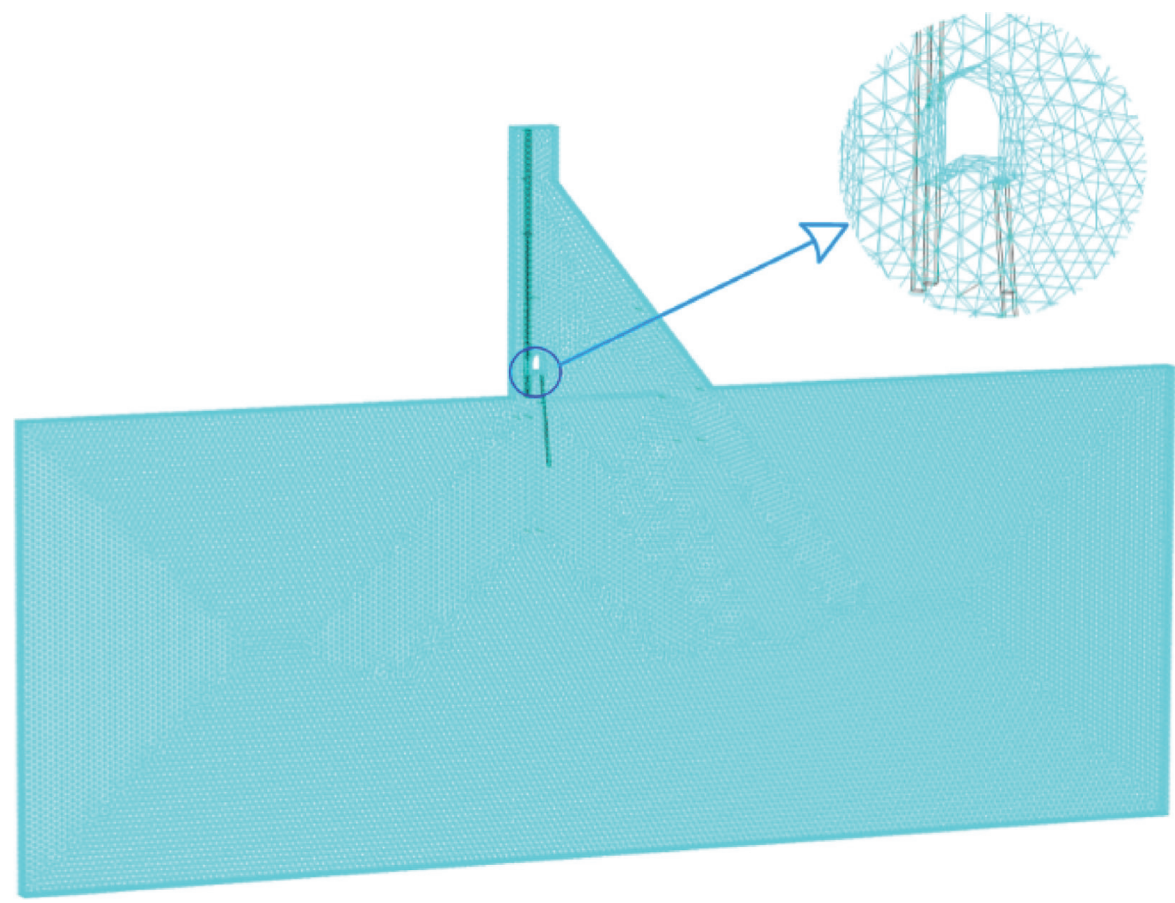

(a)

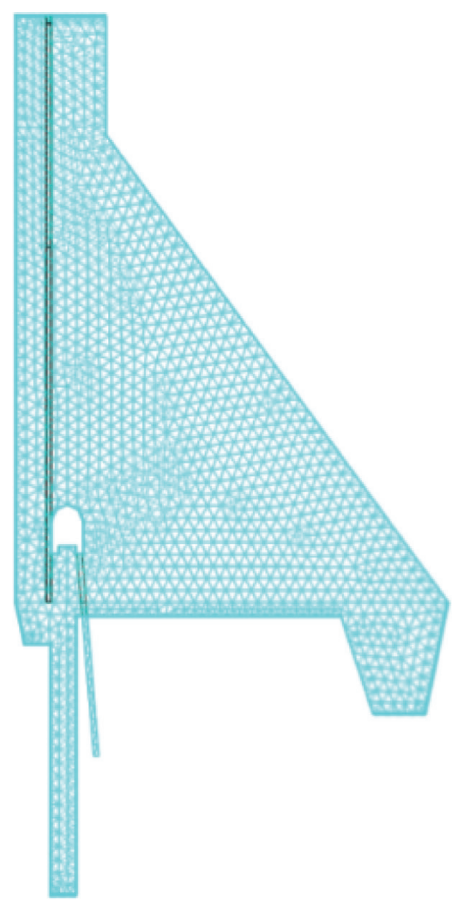

(b)

Figure 11: 3D finite element model of the Shimantan dam.

TABle 3: Calculation parameters of different materials.

\begin{tabular}{lcccc}
\hline Number & Material & Initial porosity & Initial permeability $(\mathrm{m} / \mathrm{s})$ & Initial diffusivity $\left(\mathrm{m}^{2} / \mathrm{s}\right)$ \\
\hline (1) & Normal concrete & 0.10 & $5.2 \times 10^{-9}$ & $7.11 \times 10^{-12}$ \\
(2) & Two-grade concrete & 0.13 & $5.0 \times 10^{-9}$ & $8.78 \times 10^{-12}$ \\
(3) & Three-grade concrete & 0.15 & $2.0 \times 10^{-8}$ & $9.87 \times 10^{-12}$ \\
(4) & Grout curtain & 0.15 & $1.5 \times 10^{-8}$ & $9.87 \times 10^{-12}$ \\
(5) & Rock layer & 0.20 & $2.0 \times 10^{-7}$ & $1.47 \times 10^{-11}$ \\
(6) & Drainpipe of dam body & 0.50 & $1.5 \times 10^{-4}$ & $4.50 \times 10^{-10}$ \\
(7) & Drainpipe of dam foundation & 0.50 & $3.5 \times 10^{-5}$ & $4.50 \times 10^{-10}$ \\
\hline
\end{tabular}

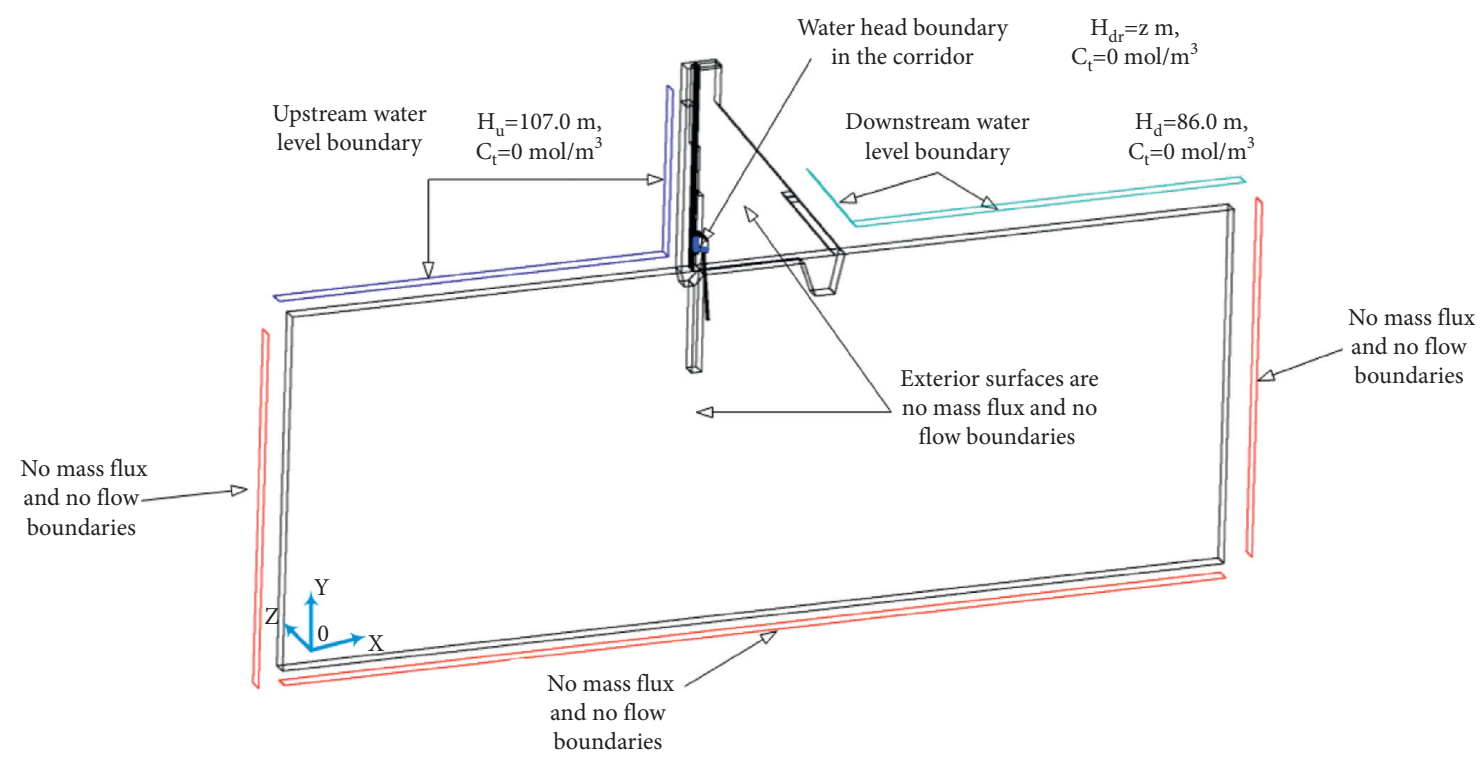

FIgURE 12: The initial and boundary conditions of the Shimantan model. 
$86 \mathrm{~m}$. The water pressure boundary in the corridors is assumed to be the potential water head, and the value equals $z$ coordinates. Exterior surfaces are no mass flux and no flow boundary. The water pressure boundary is

$$
\begin{cases}H_{u}=107 \mathrm{~m}, & \text { upstream side water level, } \\ H_{d}=86 \mathrm{~m}, & \text { downstream side water level, } \\ H_{d r}=z \mathrm{~m}, & \text { drain pile water level. }\end{cases}
$$

Calcium ion concentration on the upstream and downstream water pressure boundaries is assumed to be zero. The calcium ion concentration boundary presented in the following equation.

$$
c(t)=0 \mathrm{~mol} / \mathrm{m}^{3} .
$$

\section{Results and Discussion}

4.1. Pe Number. It is necessary to calculate the Pe number of different dam materials in the initial condition to determine which calcium compounds decomposition model. The Pe numbers in the initial state are given in Table 4 .

In the initial condition, the Pe numbers of two-grade concrete, three-grade concrete, normal concrete, and grout curtain are $115.5,30.8,117.0$, and 71.7 , and greater than 1 indicates that the calcium leaching in Shimantan concrete dam is advection-diffusion-driven leaching. In the calcium leaching process, with the decomposition of calcium compounds, the hydraulic conductivity increases gradually. Since the water level upstream and downstream is unchanged, the flow rate is increasing all the time. Eventhough the diffusion coefficient increases with porosity, judging from equations (10) and (11), the increasing rate of the diffusion coefficient is minor than hydraulic conductivity. Therefore, the decomposition model of calcium compounds should adopt the nonequilibrium model.

4.2. Total Water Head Distribution Evolution. Figure 13 shows the evolution of the overall water head distribution over a hundred years. As we can infer from the figure, when the leaching time is $0 \mathrm{a}$, the contour lines are around the face slab and the curtain. There is almost no contour line in the dam body, which indicates the good antiseepage performance of the concrete face slab and the grout curtain. The water head distribution of the dam foundation is between $86 \mathrm{~m}$ and $88 \mathrm{~m}$. When the leaching time is $10 \mathrm{a}$, the overall water head distribution is essentially the same as 0 a. There is still no contour line inside the dam, indicating that the antiseepage system works well. When the running time is $50 \mathrm{a}$, the overall water head contour line significantly changes. No contour line is concentrated around the grout curtain, suggesting that the grout curtain has lost antiseepage ability. The water head of the dam foundation rises to $88-90 \mathrm{~m}$. The $86 \mathrm{~m}$ and $88 \mathrm{~m}$ water head contours are attached to the downstream side of the dam body, which was previously around to the drainage pipe. This finding suggests that the drainage pipe of the dam foundation cannot effectively reduce the uplift pressure of the dam foundation.
There is still a dense contour distribution in the face slab, and a sudden drop of the water head appears, which indicates that the concrete face slab still has antiseepage ability after a 50-year leaching duration. When the leaching duration reaches $100 \mathrm{a}$, the distribution of the water head contour in the concrete face slab is no longer dense. The water head contour arrives inside the dam body, which indicates the concrete face slab has lost antiseepage ability.

In Figure 13, the contour lines 104 and 106 are closer to the upstream surface as shown in Figure 13(a) compared to Figure 13(d), while the contour lines 88 and 90 were closer to the downstream surface in year as shown in Figure 13(d) compared to Figure 13(a). When the leaching duration is 0 a, the grout curtain has excellent antiseepage ability. The contour lines on the upstream side of the grout curtain are denser than those on the downstream side. After 100 years of leaching duration, the grout curtain has lost antiseepage ability. The permeability of dam foundation rock is assumed to be homogeneous. Therefore, the contour lines tend to be uniformly distributed in the leaching process. The contour lines 104 and 106 are closer to the upstream surface in year 1 , while contour lines 88 and 90 are closer to the downstream surface in year 100 .

Figure 14 shows the comparison between the simulated water head distribution and monitored data. The upstream water level is $107.0 \mathrm{~m}$, and the downstream water level is $86.0 \mathrm{~m}$; the position of the piezometer tube is shown in Figure 10. The black dots and square dots were the observation data from 2003.09.11 to 2007.02.05 when the upstream water levels were $107.2 \mathrm{~m}$ and $107.1 \mathrm{~m}$, and the downstream water levels were $86.2 \mathrm{~m}$ and $85.9 \mathrm{~m}$, respectively. The corresponding leaching durations are 4 a and 8 a. For the piezometer tube $P_{9}^{2}$, the measured value stays at $92 \mathrm{~m}$ after 2005 and does not change with the upstream water level. This result may be due to clogging caused by the silt at the bottom of the piezometer tube. The observed value of this point is not representative; as a result, we omitted this value from this analysis.

As we can infer from the figure, the simulated results show good agreement with the monitoring data, indicating the accuracy of this simulation. When the leaching duration is $0 \mathrm{a}$, the water head decreases to $82.5 \mathrm{~m}$ at the position of the drainpipe and $3.5 \mathrm{~m}$ lower than the downstream water level, showing a good drainage effect. The antiseepage system reduces the water head by $24.5 \mathrm{~m}$ in total. When leached $25 \mathrm{a}$, the water head of the drainpipe is almost the same as that of the downstream side. This result shows that the drainage pipe can effectively reduce the uplift pressure of the dam foundation. When the leaching duration reaches $50 \mathrm{a}$, the grout curtain and drainage pipe have essentially lost their seepage prevention ability, and the uplift pressure of the dam foundation has increased significantly. The downstream water level reaches $89.1 \mathrm{~m}$. When the leaching duration comes $100 \mathrm{a}$, the downstream water level rises to $91.8 \mathrm{~m}$. The water head at the concrete face slab has decreased by $4 \mathrm{~m}$. We can obtain the uplift pressure by integrating the water head along the foundation surface. Compared with the initial time, the uplift pressure increased by $10.9 \%$ after 50 a leaching duration. After 100 years of leaching duration, the 
TABle 4: Pe numbers of different dam materials at initial condition.

\begin{tabular}{|c|c|c|c|c|}
\hline Dam material & Average flow rate $u(\mathrm{~m} / \mathrm{s})$ & $R(\mathrm{~m})$ & $D_{e}\left(\mathrm{~m}^{2} / \mathrm{s}\right)$ & Pe number \\
\hline Two-grade concrete & $5.07 \times 10^{-8}$ & 0.02 & $8.78 \times 10^{-12}$ & 115.5 \\
\hline Three-grade concrete & $7.60 \times 10^{-9}$ & 0.04 & $9.87 \times 10^{-12}$ & 30.8 \\
\hline Normal concrete & $4.16 \times 10^{-8}$ & 0.02 & $7.11 \times 10^{-12}$ & 117.0 \\
\hline Grout curtain & $7.08 \times 10^{-8}$ & 0.01 & $9.87 \times 10^{-12}$ & 71.7 \\
\hline
\end{tabular}

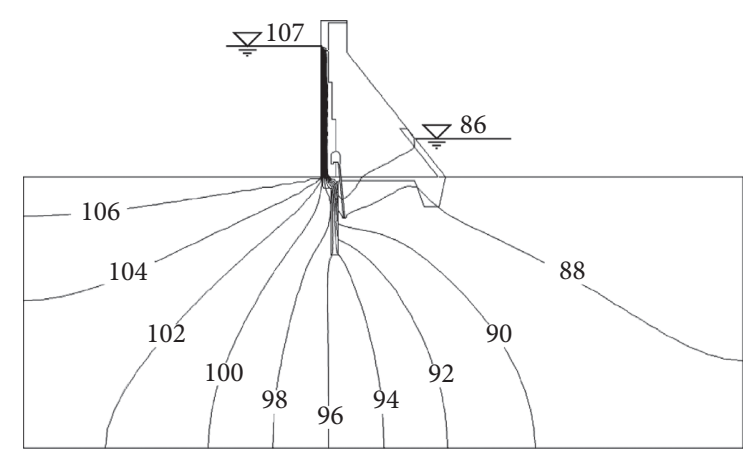

(a)

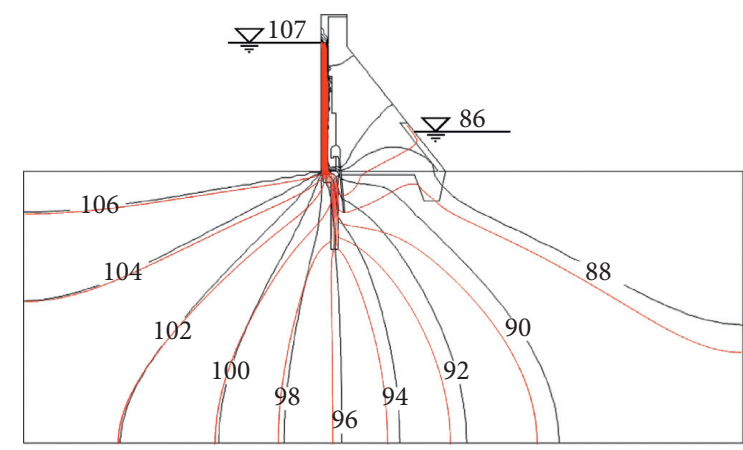

(c)

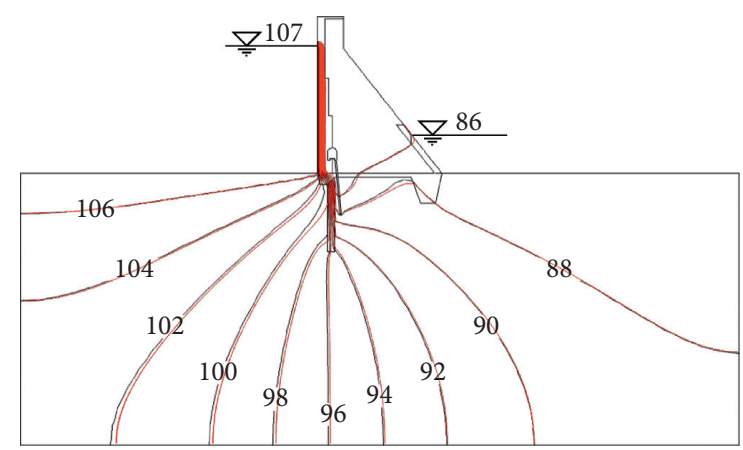

(b)

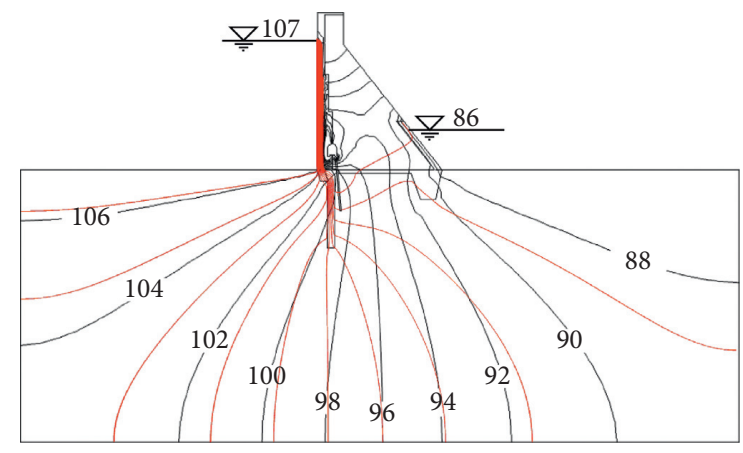

(d)

Figure 13: Evolution of the total water head distribution along the dam baseline (unit, (m)); the leaching duration is from 1 a to 100 a. (a) 0 a. (b) 10 a. (c) 50 a. (d) 100 a.

uplift pressure of the Shimantan concrete dam increased by $40.8 \%$.

4.3. Leakage Quantity Evolution. The monitored data shown in Figures 15 and 16 are the average annual leakage from measuring weirs. We calculated the simulated results from the following equation:

$$
q_{b}=\iint v \frac{L_{0}}{L_{1}} \mathrm{~d} x \mathrm{~d} z
$$

where $q_{b}$ is the dam body leakage (L/s), $v$ is the flow velocity vertical to the overflow surface $(\mathrm{m} / \mathrm{s}), L_{0}$ is the total length of the dam, $645 \mathrm{~m}$, and $L_{1}$ is the width of the numerical model, $6 \mathrm{~m}$. In this study, we assume that leakage quantity is the same in all the dam sections, ignoring the differences between the overflow and nonoverflow dam sections and the influences of the river valley.

As we can see from Figure 15, the leakage quantity of the dam body was $0.884 \mathrm{~L} / \mathrm{s}$ in 2003 and $1.151 \mathrm{~L} / \mathrm{s}$ in 2010 . The annual leakage of the dam body fluctuated, and overall, there is an increasing trend. From the comparison of numerical results and monitored data, the error of dam foundation leakage is $0.01-0.32 \mathrm{~L} / \mathrm{s}$, the error percentage is $3.48-27.46 \%$, and the average error percentage is $0.64 \%$. The simulated results are in good agreement with the monitored data, indicating the accuracy of this simulation.

Figure 16 shows the comparion of the simulated dam foundation leakage quantity and monitored data from measuring weirs. The dam foundation leakage is also taken from the average annual amount, and the numerical results are also calculated from equation (15). It is noteworthy that both the monitoring data and the simulated results include the seepage from the right sidewall of the corridor. The leakage mainly comes from the dam foundation; however, there may also be some bypass seepage flow from downstream. As we can infer from the figure, the leakage quantity of the dam foundation was $1.341 \mathrm{~L} / \mathrm{s}$ in $2003,0.457 \mathrm{~L} / \mathrm{s}$ larger than that of the dam body. In the year of 2010, the leakage quantity was $1.400 \mathrm{~L} / \mathrm{s}, 0.249 \mathrm{~L} / \mathrm{s}$ larger than that of the dam body. The annual leakage of the dam foundation also fluctuates; overall, there is an increasing trend. From the 


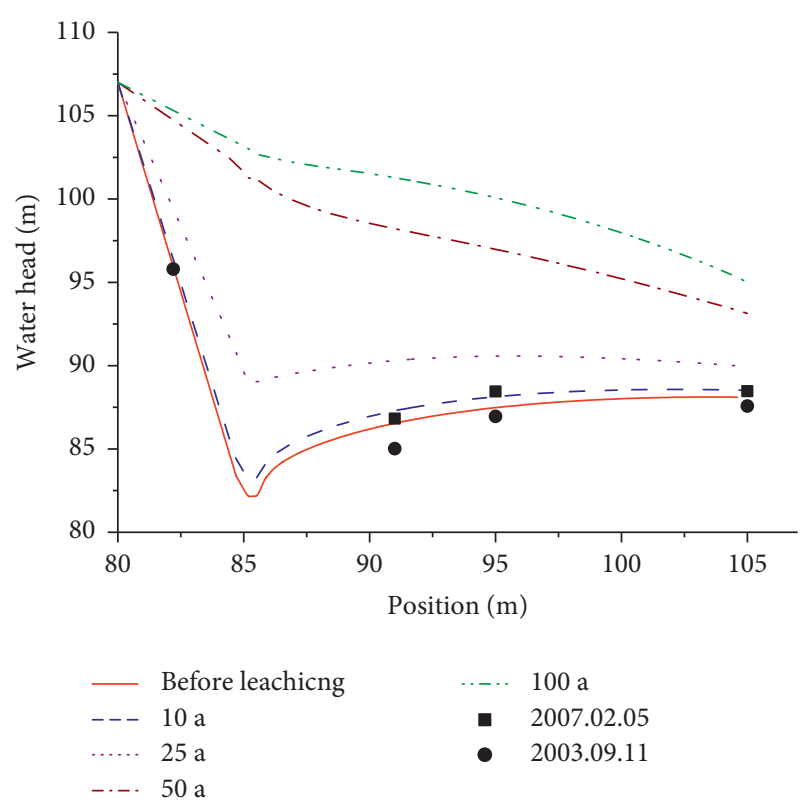

FIGURE 14: Evolution of the water head distribution along the dam baseline.

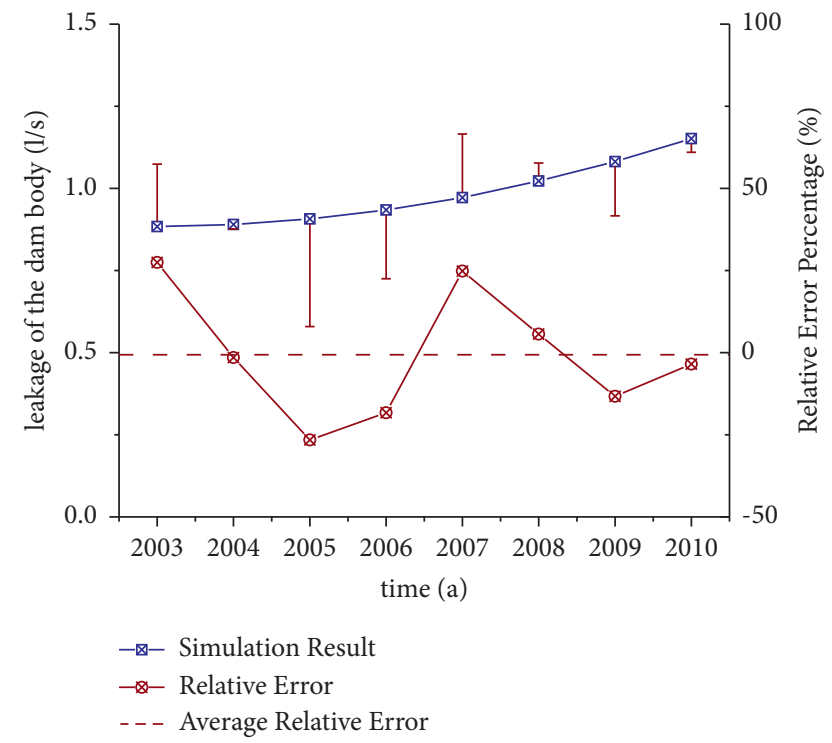

Figure 15: Comparison of the simulated dam body leakage quantity and monitored data.

comparison of numerical results and monitored data, the error of dam body leakage is $0.01-0.24 \mathrm{~L} / \mathrm{s}$, the error percentage is $0.8-21.6 \%$, and the average error percentage is $1.18 \%$. Thus, the simulated results are in good agreement with the monitored data, indicating the accuracy of this simulation.

Figure 17 shows the evolution of the dam body and dam foundation leakage quantity over a century. As we can infer from the figure, in the first ten years, the leakage of dam foundation is more significant than dam body, and then, the leakage of dam body exceeds the dam foundation. The seepage flow goes through different structures and materials

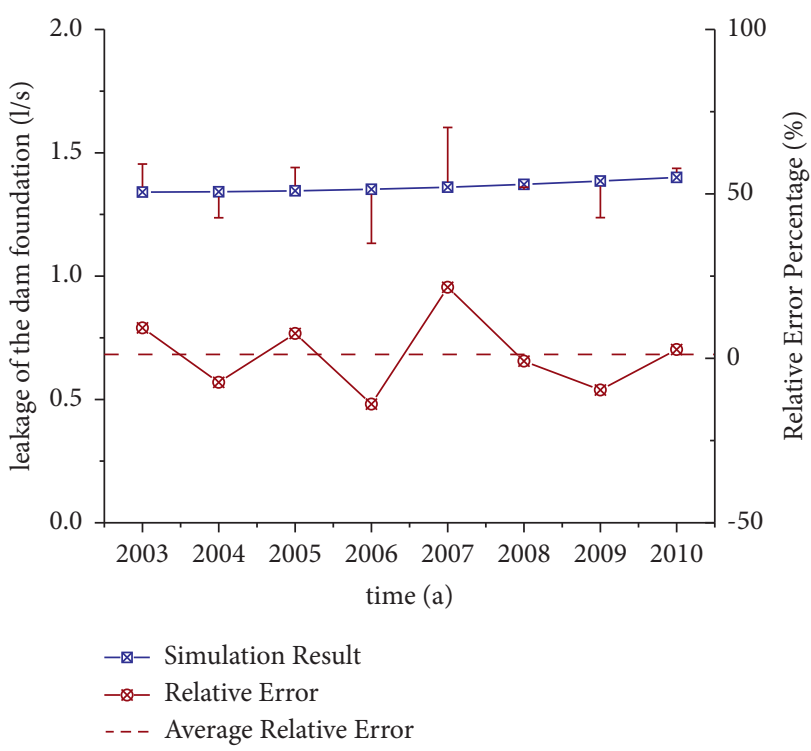

FIgURE 16: Comparison of the simulated dam foundation leakage quantity and monitored data.

for leakage in the dam foundation, including the rock and grout curtains. When the hydraulic conductivity of the curtain is higher than rock, the leakage of the dam foundation should not increase significantly. The water head distribution in Figure 13(c) indicates the hydraulic conductivity of the grout curtain is later than the rock, and the grout curtain has lost antiseepage ability. However, the leakage evolution curve still increases with the leaching duration after 2050. The leakage increase rate becomes faster and faster, probably because of the bypass seepage in the dam body. As we can infer from Figures 13(c) and 13(d), a denser distribution of water head contour in the dam body indicates that the bypass seepage around the dam body is gradually enhanced in the leaching process. For dam body leakage, the seepage flow goes through the concrete face slab. With the increase of the hydraulic conductivity of the slabs, the leakage of the dam body will increase continuously. After 100 years of leaching duration, leakage quantity of dam body and foundation rise 48 and 17 times.

4.4. Hydraulic Gradient Evolution. Figure 18 shows the evolution of the hydraulic gradient in the concrete face slab central line at $84.3 \mathrm{~m}$. The position of the central line is shown in Figure 10. We calculate the hydraulic gradient from the following equation.

$$
i=\sqrt{H_{x}^{2}+H_{y}^{2}+H_{z}^{2}}
$$

where $i$ is the hydraulic gradient, and $H_{x}, H_{y}$, and $H_{z}$ are the gradients of the water head $H$.

The maximum value of hydraulic gradient at the beginning is 11.93, which is less than the allowable value of 150 . There is a sudden drop in the area $3 \mathrm{~m}$ from the upstream side, and the lowest hydraulic gradient is 0.30 . This result occurs because of the existence of a dam body drain pipe. With the increase of leaching duration, the hydraulic 


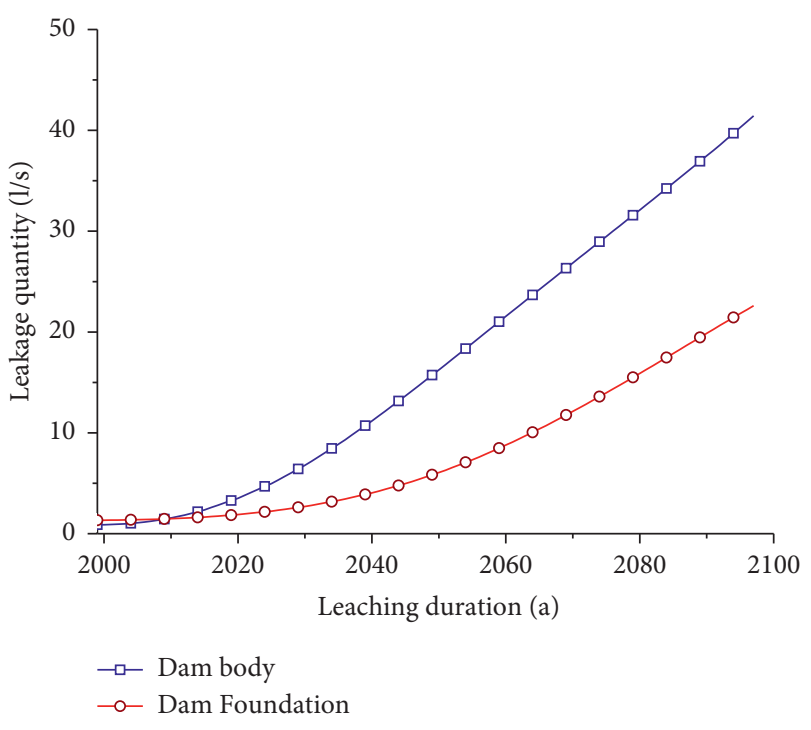

FIgURE 17: Evolution of the dam body and foundation leakage quantity over a century.

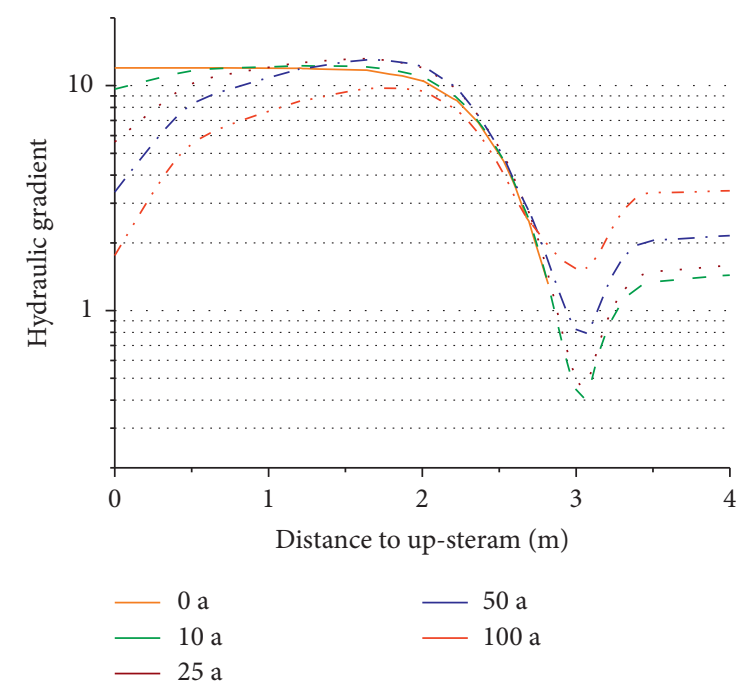

FIGURE 18: Evolution of the hydraulic gradient in the concrete face slab central line at $84.25 \mathrm{~m}$.

gradient of the upstream side decreases, while it rises slightly in the area 1-2 $\mathrm{m}$ away from the upstream side. This is due to the increase of hydraulic conductivity in the upstream concrete face slab. When leached $50 \mathrm{a}$, the upstream side hydraulic gradient decreased to 3.36 , while the region behind the drainpipe increased to 2.15 . This result is due to the decomposition of calcium compounds on the upstream side. The hydraulic conductivity of the upstream side is larger than the downstream side. When leached $100 \mathrm{a}$, the hydraulic gradient of the upstream side decreased to 1.75 , and the downstream side increased to 3.41. The increase of hydraulic gradient in the downstream side also reflects bypass seepage in the dam body.

Figure 19 shows the evolution of the hydraulic gradient in the grout curtain central line at $61.00 \mathrm{~m}$. The grout curtain

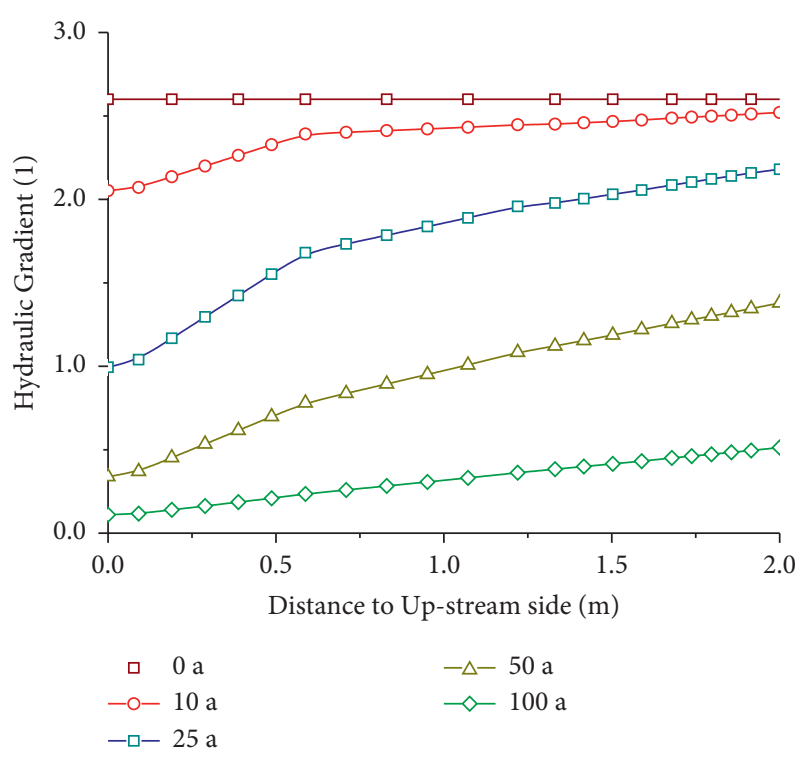

FIGURE 19: Evolution of the hydraulic gradient in the grout curtain central line at $61.00 \mathrm{~m}$.

central line is shown in Figure 10. The hydraulic gradient is 2.6 at the initial moment. As the leaching duration increases, the hydraulic gradient decreases. When the leaching duration is 100 a, the hydraulic gradient is $0.11,95.8 \%$ lower than that initially. As we can see from the evolution of the hydraulic gradient curves, the decrease of the upstream side is much faster than that of the downstream side. This result occurs because the seepage flow controls the calcium ion migration direction. Calcium ions are carried from the upstream side to the downstream side. The calcium ion concentration on the upstream side is lower than that in the other parts. As a result, the decomposition of calcium compounds is much faster, and the permeability coefficient is more significant.

4.5. Sensitivity Analysis of $\mathrm{CH}$ Content and Initial Hydraulic Conductivity. To better understand the calcium leaching process in cement-based materials, we carry out parameter sensitivity analysis of $\mathrm{CH}$ content and initial hydraulic conductivity. The total water head distribution shows that the curtain is the most vulnerable structure in the leaching process. Therefore, the evolution of $\mathrm{CH}$ concentration in the solid skeleton, hydraulic conductivity, hydraulic conductivity increase times of grout curtain with different $\mathrm{CH}$ content, and initial hydraulic conductivity are studied.

In the sensitivity analysis of $\mathrm{CH}$ content, the total calcium compound is $15,000 \mathrm{~mol} / \mathrm{m}^{3}$, and the $\mathrm{CH}$ content is $0.4,0.2,0.05$, and 0.02 . These four groups of $\mathrm{CH}$ contents are named grout curtain $A, B, C$, and $D$. In the sensitivity analysis of initial hydraulic conductivity, the initial hydraulic conductivity is $0.01 \mathrm{~K}, 0.1 \mathrm{~K}, 1.0 \mathrm{~K}, 10 \mathrm{~K}, \mathrm{~K}=1.0 \times 10^{-8} \mathrm{~m} / \mathrm{s}$. The other parameters are the same as the initial simulation.

Figure 20 shows the evolution curves of the residual $\mathrm{CH}$ in the curtain midline within 100 years. As we can see from the figure, in the whole leaching process, the $\mathrm{CH}$ 


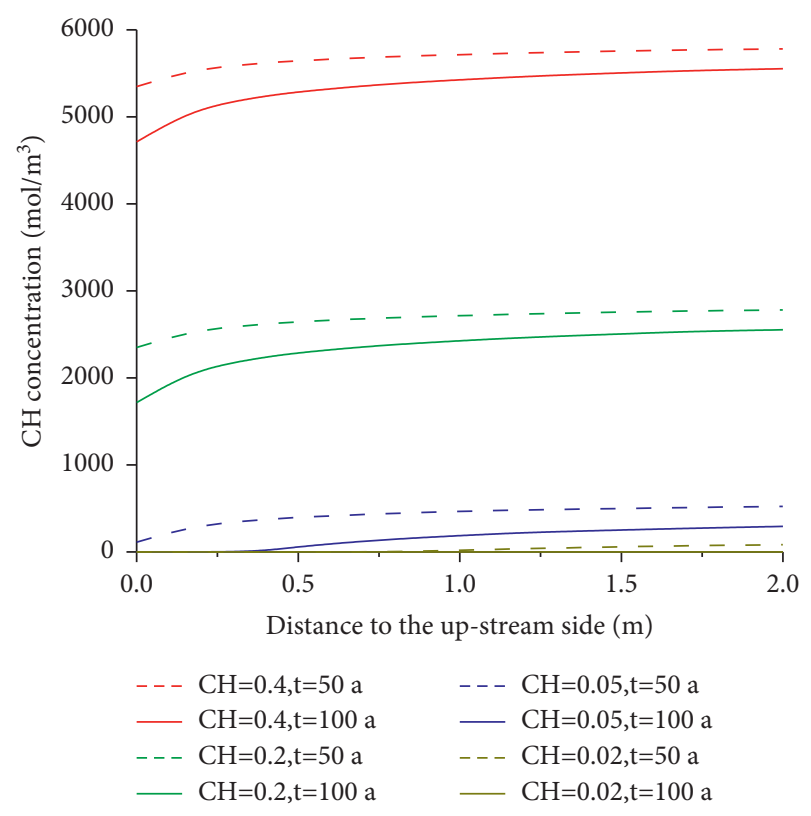

FIGURE 20: CH concentration curves of grout curtain with different initial $\mathrm{CH}$ contents.

concentration in the upstream side is lower than the downstream side, indicating the upstream side is more vulnerable to calcium leaching. When the leaching time is $50 \mathrm{a}$, the leached $\mathrm{CH}$ amount of these four grout curtains at $x=0 \mathrm{~m}$ point is $652,651,639$, and $300 \mathrm{~mol} / \mathrm{m}^{3}$, and the decomposition rate of $\mathrm{CH}$ in grout curtain $A$ is slightly faster than $B$ and $C$. For grout curtain $D$, the $\mathrm{CH}$ is totally leached within $0.7 \mathrm{~m}$. When the leaching duration is $100 \mathrm{a}$, the leached $\mathrm{CH}$ amount of these four grout curtains at $x=0 \mathrm{~m}$ point is $1287,1284,750$, and $300 \mathrm{~mol} / \mathrm{m}^{3}$. $\mathrm{CH}$ in grout curtain $\mathrm{C}$ is completely leached within $0.4 \mathrm{~m}$, and $\mathrm{CH}$ in grout curtain $C$ is totally leached.

Figure 21 shows the evolution curves of hydraulic conductivity at the grout curtain central line (elevation $75 \mathrm{~m}$ ) in $100 \mathrm{a}$. The initial hydraulic conductivity of all grout curtains is $1.5 \times 10^{-8} \mathrm{~m} / \mathrm{s}$. As we can see from Figure 21 , when the leaching duration is $50 \mathrm{a}$, the hydraulic conductivity of grout curtains $A, B$, and $C$ is almost the same. However, when the leaching duration is $100 \mathrm{a}$, the hydraulic conductivity curves of grout curtains $A, B$, and $C$ are different. Within $0.4 \mathrm{~m}$ to the upstream side, the hydraulic conductivity of grout curtains $A$ and $B$ varied from $1.0 \times$ $10^{-6} \mathrm{~m} / \mathrm{s}$ to $3.1 \times 10^{-7} \mathrm{~m} / \mathrm{s}$, and for grout curtain $C$, the hydraulic conductivity is from $3.3 \times 10^{-7} \mathrm{~m} / \mathrm{s}$ to $2.8 \times 10^{-7} \mathrm{~m} / \mathrm{s}$. Combined with the $\mathrm{CH}$ distribution, shown in Figure 20, the hydraulic conductivity increases rapidly in the $\mathrm{CH}$ decomposition stage. After the complete decomposition of $\mathrm{CH}$, the rise of the curtain hydraulic conductivity will slow down. For grout curtain $C$, because of the low initial $\mathrm{CH}$ content, after $100 \mathrm{a}$ of calcium leaching, the hydraulic conductivity order of magnitude is still $10^{-8} \mathrm{~m} / \mathrm{s}$. These results may provide a way to improve the calcium leaching durability of grout curtains. We can use additives such as fly ash or silica fumes to lower $\mathrm{CH}$ content in grout curtains [59].

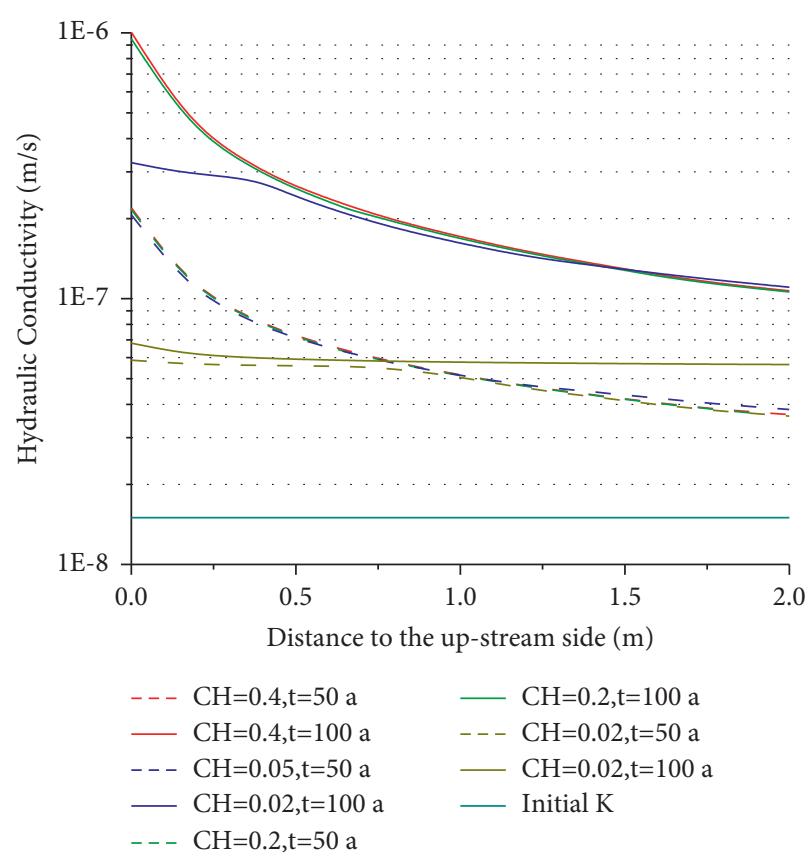

FIgURE 21: Hydraulic conductivity curves of grout curtain with different initial $\mathrm{CH}$ contents.

Furthermore, a small number of admixtures cannot effectively slow down the increase of the hydraulic gradient of the grout curtain. It is necessary to reduce the $\mathrm{CH}$ content by adding a large number of admixtures. The less $\mathrm{CH}$ content, the better the calcium leaching durability of the grout curtains.

Figure 22 shows hydraulic conductivity evolution curves of the grout curtain center line with different initial hydraulic conductivities, and the initial hydraulic conductivities are $0.01 \mathrm{~K}, 0.1 \mathrm{~K}, 1.0 \mathrm{~K}, 10 \mathrm{~K}, \mathrm{~K}=1.0 \times 10^{-8} \mathrm{~m} / \mathrm{s}$ is the actual hydraulic conductivity of the grout curtain. The upstream and downstream water levels are $107 \mathrm{~m}$ and $86 \mathrm{~m}$. The corresponding initial Pe are 5.1, 50.6, 299.4, and 544.5, and the leaching duration is $100 \mathrm{a}$. The initial $\mathrm{CH}$ and $\mathrm{C}-\mathrm{S}-\mathrm{H}$ content remain the same. As we can see from the figure, the smaller the initial hydraulic conductivity, the fewer increase times in the same time. After 100 years of leaching duration, the maximum increase is on the upstream side. For grout curtains with initial hydraulic conductivity $10 \mathrm{~K}$ and $1.0 \mathrm{~K}$, the increase times are 67.8 and 66.9, respectively. The increased times of hydraulic conductivity decrease with the distance to the upstream side. However, for grout curtains with initial hydraulic conductivity $0.1 \mathrm{~K}$ and $0.01 \mathrm{~K}$, the hydraulic conductivity increase times at the downstream side are higher than the middle part. When Pe number is more than 100, we can ignore the effect of diffusion. For these two curtains, the Pe numbers are 50.6 and 5.6. With the decrease of Pe number, the diffusion effect becomes more and more evident in the leaching process. If the hydraulic gradient is 0 , the increased hydraulic conductivity times on the upstream and downstream sides should be symmetrically distributed. Eventhough the hydraulic conductivity evolution is significantly affected by the initial hydraulic conductivity, the final hydraulic conductivity is determined by calcium composition. 


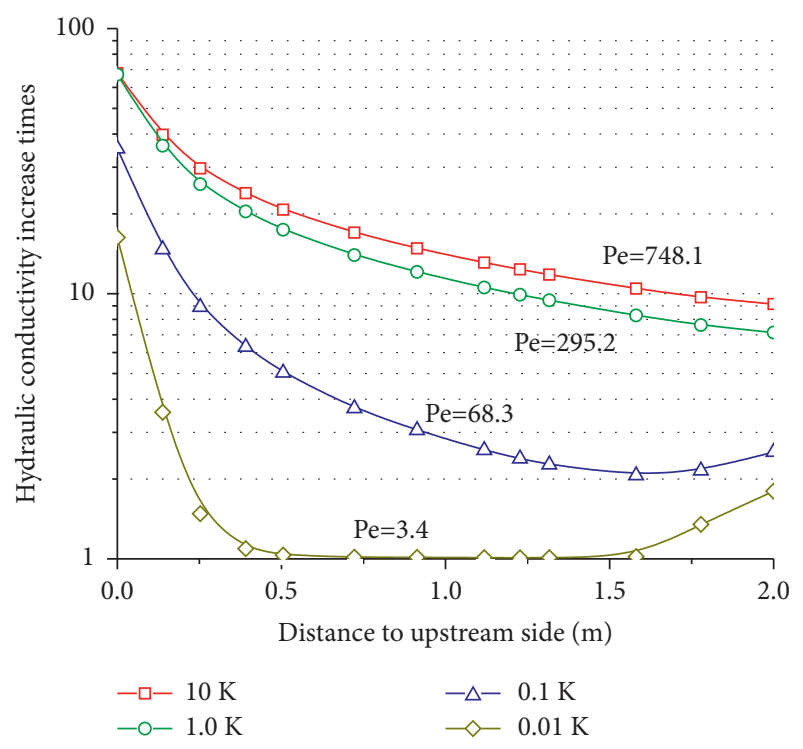

FIGURE 22: Hydraulic conductivity evolution curves of grout curtain with different initial hydraulic conductivities $\left(0.01 \mathrm{~K}, 0.1 \mathrm{~K}, 1.0 \mathrm{~K}, 10 \mathrm{~K}, \mathrm{~K}=1.0 \times 10^{-8} \mathrm{~m} / \mathrm{s}\right)$.

4.6. Discussion. In the existing advection-diffusion-driven calcium leaching model, the porosity is generally calculated with average molar volume, leading to inaccurate calculation of hydraulic conductivity. Decomposition of $\mathrm{CH}$ generates capillary pores, and decomposition of C-S-H causes gel pores and capillary pores. Furthermore, the influence of microstructure changes on hydraulic conductivity is also ignored. In this study, we proposed a new advection-diffusion-driven calcium leaching model of cement-based materials and considered that the effects of $\mathrm{CH}$ and $\mathrm{C}-\mathrm{S}-\mathrm{H}$ decomposition on pore growth are considered, respectively. In this way, on the one hand, we can use the model to study the influence of cement components on calcium leaching. On the other hand, the porosity of materials evolution can be determined more accurately. Moreover, we adopted the Kozeny-Carman (KC) relation to model the permeability coefficient evolution. In this way, the influence of microstructure changes on the permeability coefficient is taken into consideration.

$\mathrm{KC}$ relation requires evolution curves of bulk density and specific pore surface area in the leaching process. For this issue, Phung measured bulk density and specific pore surface area of intact and leached cement paste samples and assumed these two parameters are linearly varying with the decrease of $\mathrm{Ca} / \mathrm{Si}$ [3]. We adopted this assumption in this study. However, for more accurate simulation, more data of bulk density and specific pore surface are needed.

In the previous literature, the transport properties of cement-based materials are assumed invariant in the dam seepage characteristic analysis. However, due to the calcium leaching phenomenon, the hydraulic conductivity and diffusivity of cement-based materials are increasing, so the seepage characteristics of the dam are not constant. With the increase of leaching degree, the seepage characteristics change constantly. To better understand concrete dam service performance in the whole life cycle, it is necessary to analyze the seepage characteristics in the leaching process. According to the seepage characteristics evolution of the Shimantan concrete gravity dam, the following engineering measures are suggested to increase the efficiency of antiseepage systems of concrete dams and prevent calcium leaching. The main antiseepage structure of the concrete dam is the concrete face slab and the grout curtain. For the calcium leaching in the concrete face slab, we can spray the antiseepage coating such as polyurea elastomer on the upstream side of the face slab to prevent the reservoir water from penetrating. For grout curtains, it is impossible to avoid calcium leaching by spray coating materials. However, we can use admixtures such as fly ash and silica powder to reduce $\mathrm{CH}$ content. With a lower $\mathrm{CH}$ content, fewer capillary pores are produced by $\mathrm{CH}$ decomposition, and permeability coefficient increase in the calcium leaching process will significantly slow down.

In this study, the material properties of cement-based materials in concrete dams are porosity, diffusivity, hydraulic conductivity, and calcium content in the solid skeleton. The focus of this study is the calcium leaching effect on the dam seepage characteristics. In the actual operation of reservoir dams, many other factors affect the calcium leaching process, such as the stress state, water quality, and temperature. For example, the stress state of materials will affect the porosity and transport properties. Suppose the mechanical properties are considered in the analysis. It is necessary to provide the evolution of the constitutive model of the cement-based materials in the leaching process and the hydromechanical-chemical (HMC) coupling mechanism, which makes the model very complex. In this study, we ignored these factors to simplify the calculation. To solve the calcium leaching issues in hydraulic structures more accurately, the influence of these factors needs to be further studied.

\section{Summary and Conclusions}

We proposed a new mathematic model of hydrochemo behaviour of cement-based materials to investigate the concrete dam seepage characteristic evolution in the calcium leaching process. The proposed model had considered the effect of different calcium compounds decomposition on the porosity evolution. A three-dimensional finite element model of the Shimantan concrete gravity dam has been built. The water head distribution, leakage, and hydraulic gradient evolution in the leaching process were obtained. The main conclusions are as follows:

(1) The simulation results of the proposed model are consistent with previous studies. Compared with the existing model, the effect of different calcium compound decomposition is taken into consideration. The proposed model removed the effect of gel pores produced by C-S-H decomposition on transport properties. Therefore, our simulation of hydraulic conductivity and diffusion coefficient evolution is more accurate. 
(2) According to the seepage evolution of dam areas, the most important influence of calcium leaching on concrete gravity dams is the increasing uplift pressure along the dam support caused by the grout curtain's malfunction. The simulated leakage of the dam body and foundation showed good agreement with the monitoring data, indicating the rationality of this numerical modelling.

(3) After 100 years of leaching duration, leakage quantity of dam body and foundation increase 48 and 17 times. The uplift pressure of the Shimantan concrete dam increased by $40.8 \%$. The hydraulic gradient of concrete face slabs and grout curtains continued to decrease during the leaching process.

(4) Through the sensitivity analysis, the initial hydraulic conductivity significantly affected the calcium leaching rate. Calcium composition determines the final hydraulic conductivity. To obtain better calcium leaching durability, we should reduce the $\mathrm{CH}$ content as much as possible.

\section{Appendix}

\section{A. Molar Volume of C-S-H in the Leaching Process}

The molar volume of $\mathrm{C}-\mathrm{S}-\mathrm{H}$ in the leaching process is defined as

$$
V_{\mathrm{CSH}}=V_{\mathrm{CSH} 0} \cdot\left(\frac{y}{y_{0}}\right),
$$

where $V_{\mathrm{CSH}}$ is the current molar volume of C-S-H, $\mathrm{m}^{3} / \mathrm{mol}$, $V_{\mathrm{CSH} 0}$ is the initial C-S-H molar volume, $V_{\mathrm{CSH} 0}=0.04 \times 10^{-3} \mathrm{~m}^{3} / \mathrm{mol}, y_{0}$ is the initial Ca/Si ratio, and $y_{0}=1.7, y$ is the current $\mathrm{Ca} / \mathrm{Si}$ ratio. In diffusion-driven leaching, $y$ is a function of calcium concentration in pore solution [38]. However, in advection-diffusion-driven leaching, the calcium concentration in pore solution is generally lower than the equilibrium state. Therefore, $y$ is no longer a function of calcium concentration. In this study, we assume $y$ is a function of current C-S-H concentration in the solid skeleton as

$$
y=\left\{\begin{array}{l}
0.9 \cdot \frac{C_{\mathrm{CSH}}}{x_{1} / x_{2} C_{\mathrm{CSH} 0}}, \\
0.9+0.8 \frac{C_{\mathrm{CSH}}-x_{1} / x_{2} C_{\mathrm{CSH} 0}}{C_{\mathrm{CSH} 0}-x_{1} / x_{2} C_{\mathrm{CSH} 0}}
\end{array}\right.
$$

where $C_{\mathrm{CSH}}$ is the current C-S-H concentration in the solid skeleton $\left(\mathrm{mol} / \mathrm{m}^{3}\right)$, and $C_{\mathrm{CSH} 0}, x_{1}$, and $x_{2}$ are same as equation (3).

\section{B. Pore Structure Evolution in KC Relation}

The specific surface area of pores can be obtained from the Brunauer, Emmett, and Teller (BET) nitrogen gas adsorption test, and the bulk density is obtained from mercury intrusion porosimetry (MIP) measurements. Phung [3] assumed that the specific surface area of pores and the bulk density linearly vary with a decrease in the $\mathrm{Ca} / \mathrm{Si}$ ratio in a portlandite/C-S-H mixture. He also introduced the lumped term $\Omega$ to simplify the calculation of the shape factor $F_{s}$ and tortuosity $\tau$. The lumped term present in the following equation.

$$
\left\{\begin{array}{l}
\Omega=\frac{1}{\tau^{2} F_{s}}, \\
\Omega_{0}=10^{-3} \Omega_{l}, \\
\Omega=\Omega_{0}-\left(\Omega_{0}-\Omega_{l}\right) d_{l}^{2},
\end{array}\right.
$$

where $\Omega_{0}$ is the lumped term for sound materials, $\Omega_{l}$ is the lumped term for leached materials, and $d_{l}$ is the degradation degree. The degradation degree is defined as

$$
d_{l}= \begin{cases}1, & C_{\mathrm{CH}}=0, \\ \frac{C_{\mathrm{CH}}}{C_{\mathrm{CH}}^{0}}, & C_{\mathrm{CH}}>0,\end{cases}
$$

where $d_{l}$ is the leaching degree, $C_{\mathrm{CH}}^{0}$ is the initial concentration of $\mathrm{CH},\left(\mathrm{mol} / \mathrm{m}^{3}\right)$, and $\mathrm{C}_{\mathrm{CH}}$ is the current concentration of $\mathrm{CH}\left(\mathrm{mol} / \mathrm{m}^{3}\right)$.

\section{Data Availability}

All data, models, and code generated or used during the study are included within the article.

\section{Conflicts of Interest}

The authors declare that there are no conflicts of interest.

\section{Acknowledgments}

The financial support from the National Natural Science Foundation of China/Yalong River Joint Fund (U1765205), the Postgraduate Research and Practice Innovation Program of Jiangsu Province (KYCX18\0598), and the Fundamental Research Funds for the Central Universities (2018B630\X14) is gratefully acknowledged.

\section{References}

[1] M. Al-Juboori and B. Datta, "Improved optimal design of concrete gravity dams founded on anisotropic soils utilizing simulation-optimization model and hybrid genetic algorithm," ISH Journal of Hydraulic Engineering, vol. 2019, pp. 1-18, Article ID 1574614, 2019.

[2] M. Al-Juboori and B. Datta, "Performance evaluation of a genetic algorithm-based linked simulation-optimization model for optimal hydraulic seepage-related design of concrete gravity dams," Journal of Applied Water Engineering and Research, vol. 2018, pp. 1-25, Article ID 1497558, 2018.

[3] Q. T. Phung, N. Maes, D. Jacques, J. Perko, G. De Schutter, and G. Ye, "Modelling the evolution of microstructure and transport properties of cement pastes under conditions of 
accelerated leaching," Construction and Building Materials, vol. 115, no. 2, pp. 179-192, 2016.

[4] Q. T. Phung, N. Maes, D. Jacques, G. De Schutter, and G. Ye, "Investigation of the changes in microstructure and transport properties of leached cement pastes accounting for mix composition," Cement and Concrete Research, vol. 79, no. 15, pp. 217-234, 2016.

[5] Z. Lu, J. Su, and Z. Wang, "Post-evaluation of concrete quality of old dam in Fengman hydropower station," Water Power, vol. 46, no. 3, pp. 99-103, 2020, in Chinese.

[6] L. Xing and $\mathrm{S}$. $\mathrm{Xu}$, "Deterioration and its treatment of Gutianxi cascade-III dam," Water Power, vol. 31, no. 9, pp. 69-71, 2005, in Chinese.

[7] Z. Song, L. Jiang, and H. Chu, "Impact of calcium leaching on chloride diffusion behavior of cement pastes exposed to ammonium chloride aqueous solution," Construction and Building Materials, vol. 153, no. 10, pp. 211-215, 2017.

[8] E. J. Garboczi and D. P. Bentz, "Computer simulation of the diffusivity of cement-based materials," Journal of Materials Science, vol. 27, no. 8, pp. 2083-2092, 1992.

[9] C. L. Bellégo, B. Gérard, and G. Pijaudier-Cabot, "Chemomechanical effects in mortar beams subjected to water hydrolysis," Journal of Engineering Mechanics, vol. 126, no. 3, pp. 266-272, 2000.

[10] F. H. Heukamp, F.-J. Ulm, and J. T. Germaine, "Mechanical properties of calcium-leached cement pastes," Cement and Concrete Research, vol. 31, no. 5, pp. 767-774, 2001.

[11] X. Cai, Z. He, Y. Shao, and H. Sun, "Macro- and microcharacteristics of cement binders containing high volume fly ash subject to electrochemical accelerated leaching," Construction and Building Materials, vol. 116, no. 7, pp. 25-35, 2016.

[12] H. Yang, L. Jiang, Y. Zhang, Q. Pu, and Y. Xu, "Predicting the calcium leaching behavior of cement pastes in aggressive environments," Construction and Building Materials, vol. 29, no. 4, pp. 88-96, 2012.

[13] F. H. Heukamp, F.-J. Ulm, and J. T. Germaine, "Poroplastic properties of calcium-leached cement-based materials," $\mathrm{Ce}$ ment and Concrete Research, vol. 33, no. 8, pp. 1155-1173, 2003.

[14] C. Lambert, O. Buzzi, and A. Giacomini, "Influence of calcium leaching on the mechanical behavior of a rock-mortar interface: a DEM analysis," Computers and Geotechnics, vol. 37, no. 3, pp. 258-266, 2010.

[15] K. Nakarai, T. Ishida, and K. Maekawa, "Modeling of calcium leaching from cement hydrates coupled with micro-pore formation," Journal of Advanced Concrete Technology, vol. 4, no. 3, pp. 395-407, 2006.

[16] D. Kuhl and G. Meschke, "Numerical analysis of dissolution processes in cementitious materials using discontinuous and continuous Galerkin time integration schemes," International Journal for Numerical Methods in Engineering, vol. 69, no. 9, pp. 1775-1803, 2007.

[17] F. Bernard and S. Kamali-Bernard, "Performance simulation and quantitative analysis of cement-based materials subjected to leaching," Computational Materials Science, vol. 50, no. 1, pp. 218-226, 2010.

[18] A. J. Allen, J. J. Thomas, and H. M. Jennings, "Composition and density of nanoscale calcium-silicate-hydrate in cement," Nature Materials, vol. 6, no. 4, pp. 311-316, 2007.

[19] H. M. Jennings, "Aqueous solubility relationships for two types of calcium silicate hydrate," Journal of the American Ceramic Society, vol. 69, no. 8, pp. 614-618, 1986.

[20] D. Kuhl, F. Bangert, and G. Meschke, "Coupled chemomechanical deterioration of cementitious materials. part I: modeling," International Journal of Solids and Structures, vol. 41, no. 1, pp. 15-40, 2004.

[21] S. Kamali, M. Moranville, and S. Leclercq, "Material and environmental parameter effects on the leaching of cement pastes: experiments and modelling," Cement and Concrete Research, vol. 38, no. 4, pp. 578-585, 2008.

[22] S. Kamali-Bernard and F. Bernard, "Effect of tensile cracking on diffusivity of mortar: 3D numerical modelling," Computational Materials Science, vol. 47, no. 1, pp. 178-185, 2009.

[23] D. Kuhl, F. Bangert, and G. Meschke, "Coupled chemomechanical deterioration of cementitious materials part II: numerical methods and simulations," International Journal of Solids and Structures, vol. 41, no. 1, pp. 41-67, 2004.

[24] V. H. Nguyen, H. Colina, J. M. Torrenti, C. Boulay, and B. Nedjar, "Chemo-mechanical coupling behaviour of leached concrete part I: experimental results," Nuclear Engineering and Design, vol. 237, no. 20-21, pp. 2083-2089, 2007.

[25] V. H. Nguyen, B. Nedjar, and J. M. Torrenti, "Chemo-mechanical coupling behavior of leached concrete part II: modelling," Nuclear Engineering and Design, vol. 237, no. 2021, pp. 2090-2097, 2007.

[26] B. Gerard, G. Pijaudier-Cabot, and C. Laborderie, "Coupled diffusion-damage modelling and the implications on failure due to strain localisation," International Journal of Solids and Structures, vol. 35, no. 31, pp. 4107-4120, 1998.

[27] E. Stora, B. Bary, Q.-C. He, E. Deville, and P. Montarnal, "Modelling and simulations of the chemo-mechanical behaviour of leached cement-based materials: interactions between damage and leaching," Cement and Concrete Research, vol. 40, no. 8, pp. 1226-1236, 2010.

[28] F. Bangert, S. Grasberger, D. Kuhl, and G. Meschke, "Environmentally induced deterioration of concrete: physical motivation and numerical modeling," Engineering Fracture Mechanics, vol. 70, no. 7-8, pp. 891-910, 2003.

[29] G. Pijaudier-Cabot and C. L. Borderie, "Mechanical damage, chemical damage and permeability in quasi-brittle cementitious materials," European Journal of Environmental and Civil Engineerng, vol. 13, no. 7-8, pp. 963-982, 2011.

[30] V. H. Nguyen, B. Nedjar, H. Colina, and J. M. Torrenti, "A separation of scales homogenization analysis for the modelling of calcium leaching in concrete," Computer Methods in Applied Mechanics and Engineering, vol. 195, no. 52, pp. 7196-7210, 2006.

[31] E. Stora, B. Bary, Q.-C. He, E. Deville, and P. Montarnal, "Modelling and simulations of the chemo-mechanical behaviour of leached cement-based materials," Cement and Concrete Research, vol. 39, no. 9, pp. 763-772, 2009.

[32] L. Buffo-Lacarrière and A. Sellier, "Chemo-mechanical modeling requirements for the assessment of concrete structure service life," Journal of Engineering Mechanics, vol. 137, no. 9, pp. 625-633, 2011.

[33] F.-J. Ulm, J.-M. Torrenti, and F. Adenot, "Chemoporoplasticity of calcium leaching in concrete," Journal of Engineering Mechanics, vol. 125, no. 10, pp. 1200-1211, 1999.

[34] D. Gawin, F. Pesavento, and B. A. Schrefler, "Modeling of cementitious materials exposed to isothermal calcium leaching, considering process kinetics and advective water flow. part 1: theoretical model," International Journal of Solids and Structures, vol. 45, no. 25-26, pp. 6221-6240, 2008.

[35] D. Gawin, F. Pesavento, and B. A. Schrefler, "Modeling of cementitious materials exposed to isothermal calcium leaching, considering process kinetics and advective water flow. part 2: numerical solution," International Journal of Solids and Structures, vol. 45, no. 25-26, pp. 6241-6248, 2008. 
[36] D. Gawin, M. Koniorczyk, and F. Pesavento, "Modelling of hydro-thermo-chemo-mechanical phenomena in building materials," Bulletin of the Polish Academy of Sciences, Technical Sciences, vol. 61, no. 1, pp. 51-63, 2013.

[37] E. Zhao, C. Wu, S. Wang, J. Hu, and W. Wang, "Seepage dissolution effect prediction on aging deformation of concrete dams by coupled chemo-mechanical model," Construction and Building Materials, vol. 237, no. 3, pp. 1-13, 2020.

[38] B. Gérard, C. L. Bellego, and O. Bernard, "Simplified modelling of calcium leaching of concrete in various environments," Materials and Structures, vol. 35, no. 10, pp. 632-640, 2002.

[39] K. Wan, Y. Li, and W. Sun, "Experimental and modelling research of the accelerated calcium leaching of cement paste in ammonium nitrate solution," Construction and Building Materials, vol. 40, no. 5, pp. 832-846, 2013.

[40] Z. Kou and M. Dejam, "Dispersion due to combined pressuredriven and electro-osmotic flows in a channel surrounded by a permeable porous medium," Physics of Fluids, vol. 31, no. 5, Article ID 056603, 2019.

[41] M. Dejam and H. Hassanzadeh, "Diffusive leakage of brine from aquifers during $\mathrm{CO}_{2}$ geological storage," Advances in Water Resources, vol. 111, pp. 36-57, 2018.

[42] M. Dejam, "Hydrodynamic dispersion due to a variety of flow velocity profiles in a porous-walled microfluidic channel," International Journal of Heat and Mass Transfer, vol. 136, pp. 87-98, 2019.

[43] K. Wan, L. Li, and W. Sun, "Solid-liquid equilibrium curve of calcium in $6 \mathrm{~mol} / \mathrm{L}$ ammonium nitrate solution," Cement and Concrete Research, vol. 53, pp. 44-50, 2013.

[44] B. Gerard, C. L. Bellego, and O. Bernard, "Simplified modelling of calcium leaching of concrete in various environments," Materials and Structures, vol. 38, no. 12, pp. 632-640, 2002.

[45] J. Jain and N. Neithalath, "Analysis of calcium leaching behavior of plain and modified cement pastes in pure water," Cement and Concrete Composites, vol. 31, no. 3, pp. 176-185, 2009.

[46] T. M. Squires and S. R. Quake, "Microfluidics: fluid physics at the nanoliter scale," Reviews of Modern Physics, vol. 77, no. 3, pp. 977-1026, 2005.

[47] Z. Dou, X. Zhang, Z. Chen, Y. Yang, C. Zhuang, and C. Wang, "Effects of cemented porous media on temporal mixing behavior of conservative solute transport," Water, vol. 11, no. 6, p. 1204, 2019.

[48] T. K. Perkins and O. C. Johnston, "A review of diffusion and dispersion in porous media," Society of Petroleum Engineers, vol. 3, no. 1, pp. 70-84, 1963.

[49] A. Morandeau, M. Thiéry, and P. Dangla, "Investigation of the carbonation mechanism of $\mathrm{CH}$ and $\mathrm{C}-\mathrm{S}-\mathrm{H}$ in terms of kinetics, microstructure changes and moisture properties," Cement and Concrete Research, vol. 56, pp. 153-170, 2014.

[50] H. Saito and A. Deguchi, "Leaching tests on different mortars using accelerated electrochemical method," Cement and Concrete Research, vol. 30, no. 11, pp. 1815-1825, 2000.

[51] Q. T. Phung, N. Maes, G. De Schutter, D. Jacques, and G. Ye, "Determination of water permeability of cementitious materials using a controlled constant flow method," Construction and Building Materials, vol. 47, no. 10, pp. 1488-1496, 2013.

[52] A. K. Chandrappa and K. P. Biligiri, "Comprehensive investigation of permeability characteristics of pervious concrete: a hydrodynamic approach," Construction and Building Materials, vol. 123, pp. 627-637, 2016.

[53] N. Henderson, J. C. Brêttas, and W. F. Sacco, "A three-parameter Kozeny-Carman generalized equation for fractal porous media," Chemical Engineering Science, vol. 65, no. 15, pp. 4432-4442, 2010.

[54] D. P. Bentz, "Influence of silica fume on diffusivity in cementbased materials," Cement and Concrete Research, vol. 30, no. 7, pp. 1121-1129, 2000.

[55] D. P. Bentz, O. M. Jensen, A. M. Coats, and F. P. Glasser, "Influence of silica fume on diffusivity in cement-based materials," Cement and Concrete Research, vol. 30, no. 6, pp. 953-962, 2000.

[56] E. Samson and J. Marchand, "Modeling the effect of temperature on ionic transport in cementitious materials," $\mathrm{Ce}$ ment and Concrete Research, vol. 37, no. 3, pp. 455-468, 2007.

[57] B. Gérard and J. Marchand, "Influence of cracking on the diffusion properties of cement-based materials: part I: influence of continuous cracks on the steady-state regime," Cement and Concrete Research, vol. 30, no. 1, pp. 37-43, 2000.

[58] R. J. van Eijk and H. J. H. Brouwers, "Study of the relation between hydrated portland cement composition and leaching resistance," Cement and Concrete Research, vol. 28, no. 6, pp. 815-828, 1998.

[59] A. K. Chandrappa and K. P. Biligiri, "Influence of mix parameters on pore properties and modulus of pervious concrete: an application of ultrasonic pulse velocity," Materials and Structures, vol. 49, no. 12, pp. 5255-5271, 2016. 